\title{
Ice nucleation by surrogates for atmospheric mineral dust and mineral dust/sulfate particles at cirrus temperatures
}

\author{
C. M. Archuleta, P. J. DeMott, and S. M. Kreidenweis \\ Department of Atmospheric Science, Colorado State University, Fort Collins, 80523-1371 Colorado, USA
}

Received: 14 April 2005 - Published in Atmos. Chem. Phys. Discuss.: 30 May 2005

Revised: 15 September 2005 - Accepted: 16 September 2005 - Published: 4 October 2005

\begin{abstract}
This study examines the potential role of some types of mineral dust and mineral dust with sulfuric acid coatings as heterogeneous ice nuclei at cirrus temperatures. Commercially-available nanoscale powder samples of aluminum oxide, alumina-silicate and iron oxide were used as surrogates for atmospheric mineral dust particles, with and without multilayer coverage of sulfuric acid. A sample of Asian dust aerosol particles was also studied. Measurements of ice nucleation were made using a continuous-flow icethermal diffusion chamber (CFDC) operated to expose sizeselected aerosol particles to temperatures between -45 and $-60^{\circ} \mathrm{C}$ and a range of relative humidity above ice-saturated conditions. Pure metal oxide particles supported heterogeneous ice nucleation at lower relative humidities than those required to homogeneously freeze sulfuric acid solution particles at sizes larger than about $50 \mathrm{~nm}$. The ice nucleation behavior of the same metal oxides coated with sulfuric acid indicate heterogeneous freezing at lower relative humidities than those calculated for homogeneous freezing of the diluted particle coatings. The effect of soluble coatings on the ice activation relative humidity varied with the respective uncoated core particle types, but for all types the heterogeneous freezing rates increased with particle size for the same thermodynamic conditions. For a selected size of $200 \mathrm{~nm}$, the natural mineral dust particles were the most effective ice nuclei tested, supporting heterogeneous ice formation at an ice relative humidity of approximately $135 \%$, irrespective of temperature. Modified homogeneous freezing parameterizations and theoretical formulations are shown to have application to the description of heterogeneous freezing of mineral dust-like particles with soluble coatings.
\end{abstract}

Correspondence to: P. J. DeMott

(pdemott@lamar.colostate.edu)

\section{Introduction}

In order to unravel the intricacies of climate change, it is important to include the role of cirrus clouds. The net impact of cirrus clouds on the Earth's climate system is determined by the balance between the reflectance of incoming solar radiation back to space and the trapping of outgoing infrared fluxes emitted from the Earth's surface. These net radiative impacts are determined by the microphysical composition, altitude and frequency of formation of cirrus clouds (e.g. Stephens et al., 1990). Upper tropospheric aerosols indirectly affect these physical properties through their role in the ice formation process. The salient ice nucleation processes are homogeneous freezing and heterogeneous nucleation and their relative roles in cirrus ice formation are presently unclear. Because heterogeneous nucleation is effective at warmer temperatures and possibly at lower relative humidities than homogeneous freezing nucleation, even relatively modest populations of ice nuclei (IN) can have substantial impacts on the conditions under which cirrus clouds form (DeMott et al., 1994). The impacts of heterogeneous nucleation on the formation of cirrus clouds could have implications for the extent and duration of cirrus cloud cover, which ultimately impacts climate.

Mineral dusts from the arid regions of the Asiatic continent were implicated as possible heterogeneous ice nuclei over 40 years ago (Isono et al., 1959). More recently, evidence has emerged indicating that mineral particles reach upper tropospheric altitudes where they may serve as ice nuclei in cirrus clouds. In an aircraft campaign conducted over the Alps, Heintzenberg et al. (1996) found that minerals were common constituents in cirrus crystal residues. Upper tropospheric IN activated in a diffusion chamber and subsequently collected by impaction (Chen et al., 1998) also had enhanced number fractions of crustal particles when compared with the ambient aerosol population. A lidar study by Sassen (2002) suggests that cirrus-like ice clouds form at the top of layers

(C) 2005 Author(s). This work is licensed under a Creative Commons License. 


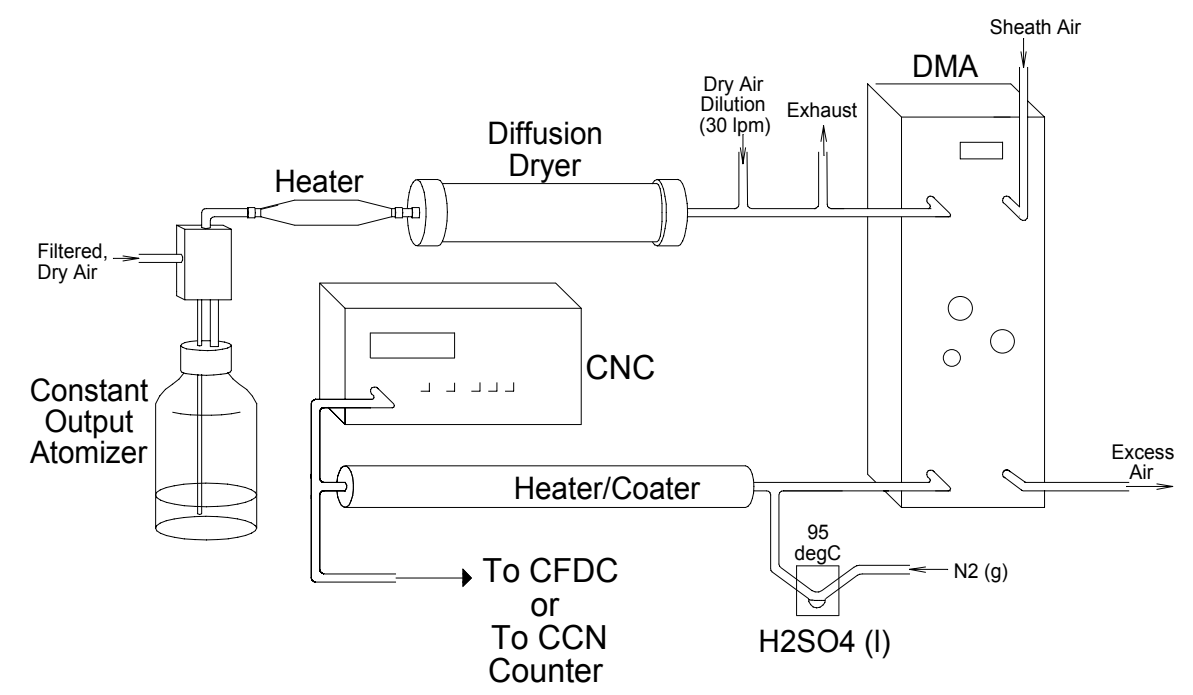

Fig. 1. Schematic of the aerosol particle generation and classification system. Particle suspensions are atomized in the constant output atomizer and dried using a heater, diffusion dryer and dry air dilution. Particles are then size selected using the DMA (with charge neutralizer) and combined, when desired, with sulfuric acid droplets which evaporate and condense on the particles in the heater/coater. Particle count is then measured with a CNC while either cloud condensation activity (CCN counter) or ice nucleation activity (CFDC) is measured.

of transported Asian aerosols, at temperatures considerably warmer than the climatological mean temperature for midlatitude cirrus formation. DeMott et al. (2003a) detected concentrations of heterogeneous ice nuclei exceeding $1 \mathrm{~cm}^{-3}$, up to 100 times higher than typical background values, in and above the marine boundary layer in Florida during Saharan dust episodes. These nuclei were within atmospheric layers feeding thunderstorm development and subsequent cirrus anvil formation. Measurements of high mineral dust fractions in residual particles from anvil cirrus during that study (Cziczo et al., 2004) and cloud model simulations of these cases (Van den Heever et al., 2005) support the hypothesis that the dust ice nuclei modified cloud microphysics and dynamics. Sassen et al. (2003) documented glaciation of altocumuli forming at the top of the dust layer at $-8^{\circ} \mathrm{C}$ during one of the same episodes. Finally, DeMott et al. (2003b) found mineral dusts as the major component of free tropospheric ice nuclei processed for cirrus conditions even during a period without strong influence from dust transports.

Dust particles are sometimes found in the upper troposphere without significant sulfate or other condensed components (DeMott et al., 2003b), but these particles can also become coated with aqueous solutions of sulfates, nitrates and other electrolytes when passing through marine or polluted continental regions (Zhang and Carmichael, 1999). Grassian (2002) describes the role of many types of mineral dusts in the irreversible uptake and surface reaction with nitric acid. Dentener et al. (1996) calculate that $50-70 \%$ of particulate sulfate in the vicinity of dust source regions is associated with mineral aerosol. Recent laboratory studies also indicate the possible role of clays or mineral dust components internally mixed with sulfate in particles as effective heterogeneous ice nuclei (Zuberi et al., 2002; Hung et al., 2003).

The current study focuses on the role of mineral aerosols as likely insoluble components of heterogeneous IN. Experiments were performed to expose nearly monodisperse samples of the submicrometer aerosols $(50-200 \mathrm{~nm}$ in diameter) to cirrus-relevant temperatures between -45 and $-60^{\circ} \mathrm{C}$ and a range of relative humidity above ice-saturated conditions $\left(R H_{i}\right)$ to map out regions of $R H_{i}$ and temperature space where significant ice nucleation rates occur. The heterogeneous ice nucleation rates of submicrometer iron oxide, aluminum oxide and alumina-silicate particles were quantified, in their pure states and as multi-component particles with soluble $\mathrm{H}_{2} \mathrm{SO}_{4}$ coatings. The ice nucleation rates of a sample of reference Asian dust were also measured.

\section{Methods}

The experimental methods used to generate test aerosols, characterize them for size and soluble content and then measure their ice nucleation activity are summarized in Fig. 1. Powder samples were continuously atomized from aqueous suspensions using a constant output atomizer, dried, size selected using a differential mobility analyzer (DMA), and for some studies, coated with sulfuric acid as described in the following section. Particles were then sent to a condensation nuclei counter (CNC) to measure total number concentrations and simultaneously either to a cloud condensation nuclei $(\mathrm{CCN})$ counter or through a temperature and humidity pre-conditioner to the continuous flow diffusion chamber (CFDC). The latter instrument detects ice nucleation. 


\subsection{Aerosol generation}

Aluminum oxide $\left(\mathrm{Al}_{2} \mathrm{O}_{3}\right)$, alumina-silicate $\left(3 \mathrm{Al}_{2} \mathrm{O}_{3}: 2 \mathrm{SiO}_{2}\right)$ and iron oxide $\left(\mathrm{Fe}_{2} \mathrm{O}_{3}\right)$ nanoscale particles were obtained commercially (NanoProducts Corporation, Longmont, CO, USA). The particles were prepared via spray pyrolysis of aqueous metal salt solutions. Crystallite sizes as determined by $\mathrm{x}$-ray diffraction are quoted by the manufacturer as 13 to $19 \mathrm{~nm}$ for aluminum oxide and 37 to $39 \mathrm{~nm}$ for iron oxide. The alumina-silicate particles are amorphous. The degree of residual contamination by the precursor salts, if any, was not reported. A sample of Asian mineral dust was collected and prepared for analysis by the National Institute for Environmental Studies in Japan. The dust sample was obtained originally as a soil sample from the Tengger desert of China. Sample preparation involved sieving the dust with a wind tunnel system, and using a cyclone impactor to remove particles larger than $10 \mu \mathrm{m}$. The composition of the remaining fine dust is typical of what is found aloft following desert dust storms over Asia (Mori et al., 2002).

Reservoir solutions for the atomizer (TSI Model 3076) consisted of 1.0 weight percent mixtures of the dust particles suspended (by stirring) in high purity water. The particle stream was dried via passage through a heater $\left(60^{\circ} \mathrm{C}\right)$ and diffusion dryer. Filtered compressed air was then introduced to promote additional drying and to lower particle number density. From this 30 liter per minute polydisperse particle stream a DMA (TSI Model 3071A), including an upstream $2 \mathrm{mC} \mathrm{Kr}-85$ bipolar charge neutralizer, pulled off $1000 \mathrm{~cm}^{3} \mathrm{~min}^{-1}$. The DMA, using a 10:1 sheath to sample ratio, produced nearly monodisperse fractions of particles centered at sizes of 50,100 and $200 \mathrm{~nm}$ for experiments. Measurements of the full particle size distribution and calculations of DMA multiple charging (Weidensohler, 1988) were used to estimate the contributions of larger aerosols to the size-selected particles. For $50 \mathrm{~nm}$ selected particles produced from solutions of the manufactured nanoparticles, $72 \mathrm{~nm}$ particles were also present as approximately 3 to $4 \%$ of the total numbers generated. For $100 \mathrm{~nm}$ selected nanoparticles, $149 \mathrm{~nm}$ and $191 \mathrm{~nm}$ particles were also present as 10 to $12 \%$ and 0.8 to $1.6 \%$, respectively, of the total numbers generated. For $200 \mathrm{~nm}$ nanoparticles, $317 \mathrm{~nm}$ particles were also present at 12 to $15 \%$ levels. For the Asian dust particles, $50 \mathrm{~nm}$ selected particles were predicted to contain $2.5 \%$ at a size of $72 \mathrm{~nm} ; 100 \mathrm{~nm}$ particles were predicted to contain $6.4 \%$ at $149 \mathrm{~nm}$ and $0.5 \%$ at $191 \mathrm{~nm} ; 200 \mathrm{~nm}$ particles were predicted to contain $2.2 \%$ at $317 \mathrm{~nm}$. The production of larger particles due to multiple charging was thus most limited for the natural dust sample. This was due to the overall particle size distribution from atomization/drying of this sample having a mode size near $35 \mathrm{~nm}$, with an order of magnitude lower particle numbers at a size of $200 \mathrm{~nm}$ (Fig. 2). Thus, the atomization process was very effective at removing any supermicron particles.

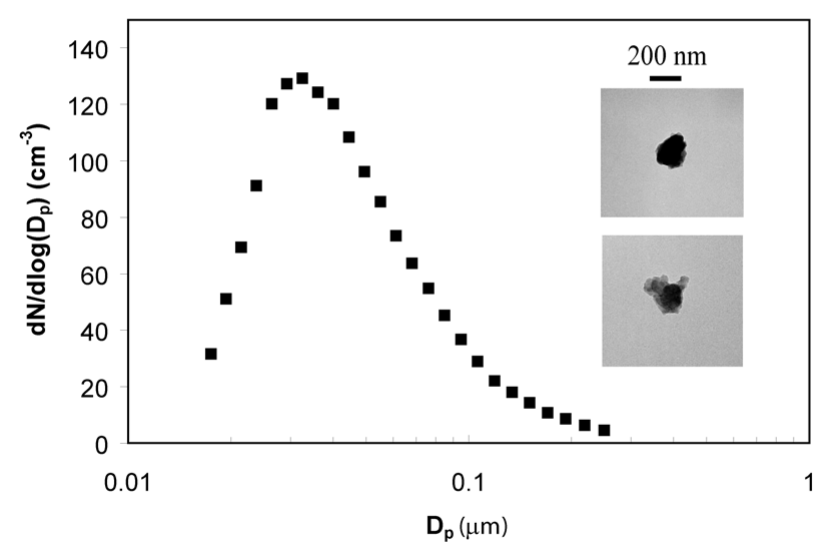

Fig. 2. Size distribution of Asian dust sample measured by the DMA following atomization and drying. The inset transmission electron microscope (TEM) images show representative sizeselected particles (200 $\mathrm{nm}$ in this case) collected (by impaction) of the ice crystals they nucleated in the CFDC. The elemental composition of the upper particle indicated $\mathrm{Si}, \mathrm{Al}, \mathrm{Fe}, \mathrm{P}$ and $\mathrm{K}$ in order of predominance while the lower particle contained only $\mathrm{Si}, \mathrm{Al}$ and $\mathrm{Fe}$ above background. Some other particles contained $\mathrm{Ca}$ and $\mathrm{Mg}$. Absence of $\mathrm{S}$ in most is consistent with the inability to detect the relatively low level of soluble matter found from water uptake measurements.

While it is assumed that strong drying of atomized particles mitigated any potential influence of water exposure on subsequent ice nucleation processes, wet generation may have redistributed any soluble matter in the samples across the generated aerosol distribution. Characterization of soluble content of untreated particles is described in the next section.

Sulfuric acid was condensed onto surrogate dust particles to promote water uptake and $\mathrm{CCN}$ activity using the method described by Han and Martin (2001). Sulfuric acid droplets, produced by heating and re-condensation in $\mathrm{N}_{2}$ carrier gas, were mixed with monodisperse mineral dust particles from the DMA. The combined particle stream entered an insulated Pyrex tube wrapped with a resistive heating element in steadily decreasing pitch to initially re-volatilize the sulfuric acid at $200^{\circ} \mathrm{C}$ and re-condense it onto the mineral dust cores as the stream steadily cooled, with nearly a linear gradient, to room temperature. The result was a stream of monodisperse dust cores coated with sulfuric acid.

\subsection{Characterization of soluble matter and soluble coatings}

The cloud condensation nuclei ( $\mathrm{CCN})$ activity of the dust aerosols treated with $\mathrm{H}_{2} \mathrm{SO}_{4}$ was used to determine the amount of $\mathrm{H}_{2} \mathrm{SO}_{4}$ that deposited onto the insoluble particles, a critical factor in estimating their $\mathrm{H}_{2} \mathrm{SO}_{4}-\mathrm{H}_{2} \mathrm{O}$ compositions in freezing experiments. Simultaneous measurements with a CCN counter (CCNC), a static thermal gradient diffusion chamber, described by DeMott (1995), and a condensation 


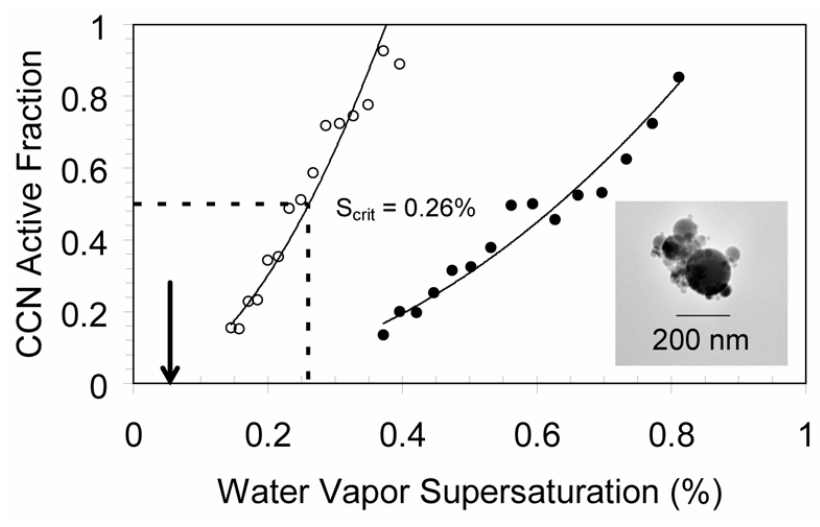

Fig. 3. Measured CCN activity for $200 \mathrm{~nm}$ alumina-silicate particles. Symbols indicate cases of untreated particles (closed circles) and particles treated with $\mathrm{H}_{2} \mathrm{SO}_{4}$ (open circles). The lines indicate exponential fits to the data, and $S_{\text {crit }}$ is the point on the line where $50 \%$ of the particles have activated as CCN. The critical supersaturation of a $200 \mathrm{~nm}$ pure sulfuric acid solution particle is indicated by the arrow. The insert shows a TEM image of a treated $200 \mathrm{~nm}$ core-sized alumina-silicate particle collected (by impaction) of the ice crystal it nucleated in the CFDC.

nuclei counter (CNC, TSI Model 3025A) were used to determine the critical water vapor supersaturation $\left(S_{\text {crit }}\right)$ at which half of the particles activated as $\mathrm{CCN}$ (at $25^{\circ} \mathrm{C}$ ). The $\mathrm{CCNC}$ sample volume and supersaturation calibration were checked prior to these studies using known sizes and concentrations of ammonium sulfate particles. Köhler theory for spherical particles of soluble material having insoluble, spherical cores (e.g. Pruppacher and Klett, 1997) was used to relate $S_{\text {crit }}$ of the mean size particles to the soluble weight percent of $\mathrm{H}_{2} \mathrm{SO}_{4}$, assuming that the acid/water coating formed a perfect shell. Property data for $\mathrm{H}_{2} \mathrm{SO}_{4}-\mathrm{H}_{2} \mathrm{O}$ solutions were determined following DeMott et al. (1997) and water activity was based on Clegg et al. (1998).

Figure 3 shows an example of the effect of soluble coating on CCN activation by alumina-silicate particles. The particles were significantly more active as $\mathrm{CCN}$ after passing through the $\mathrm{H}_{2} \mathrm{SO}_{4}$ coating system. The expected activation condition for a pure, $200-\mathrm{nm} \mathrm{H}_{2} \mathrm{SO}_{4}$ particle is also shown. The impact of particle morphology on $\mathrm{CCN}$ activation is not known. The spherical primary particle and agglomerate morphology shown in the image inset was typical of all manufactured particles used in this study, although it represents the most extreme situation; namely, the largest particles examined and most agglomerate component particles. It is also important to point out that the morphology presented in the image of Fig. 3 may not necessarily be the morphology at the point of ice nucleation for results described in Sect. 3 . The particle in Fig. 3 was collected onto a microscope grid initially as an impacted ice crystal (cf., Kreidenweis et al., 1998) that had nucleated in the continuous flow diffusion chamber (see next section), and was subsequently evaporated and melted on the grid prior to later examination by transmission electron microscopy. Consideration of agglomerate effects on nucleation rate calculations is described later in this paper.

The estimated weight fractions of sulfuric acid deposited on the treated mineral particles are summarized in Table 1. The bulk densities of insoluble cores used in this calculation were 5.24, 4.0 and $3.16 \mathrm{~g} \mathrm{~cm}^{-3}$ for $\mathrm{Fe}_{2} \mathrm{O}_{3}, \mathrm{Al}_{2} \mathrm{O}_{3}$ and alumina-silicate particles, respectively. Weight percent acid coverage ranged from 1.6 to $7 \%$. The approximate corresponding number of monolayers of acid is indicated, calculated by assuming spherical particles with uniform coverage and using the estimate that a simple, close-packed sphere model for $\mathrm{H}_{2} \mathrm{SO}_{4}$ gives about $4.5 \times 10^{14}$ molecules $/ \mathrm{cm}^{2}$ (Wyslouzil et al., 1994). A range of acid coatings from 2.9 to 7.1 monolayers with an average of 4.7 was thus inferred. The number concentrations of $50 \mathrm{~nm}$ particles generated by atomization of the colloidal suspensions were not sufficient for accurate determination of their $\mathrm{CCN}$ activation conditions. For example, two particles in the CCNC sample volume reflects concentrations of $35 \mathrm{~cm}^{-3}$, sufficient number concentrations for ice nucleation experiments but inadequate numbers for determining the $50 \% \mathrm{CCN}$ activation. Results did not suggest that soluble content continued the modest trend toward higher sulfuric acid weight fraction versus smaller size that is apparent in Table 1. Therefore, an intermediate weight fraction of 0.035 was assumed for all treated $50 \mathrm{~nm}$ core particles for use in inferring the water activity and composition in ice nucleation studies.

Modest CCN activity was noted for untreated particles, greater than expected for an insoluble, but completely wettable nucleus $(\sim 1 \%$ water vapor supersaturation for an insoluble $200 \mathrm{~nm}$ particle); this may be a consequence of contamination introduced in the manufacturing process and/or the atomization procedure. Assuming sulfuric acid as the solute for reference, $S_{\text {crit }}$ values of $0.58,0.63$, and $0.66 \%$ for $200 \mathrm{~nm}$ aluminum oxide, alumina-silicate and iron oxide particles, gave a range from 0.2 to $0.5 \%$ soluble content present in the untreated particles. The nature of this soluble matter was not determined. Water uptake measurements at $30^{\circ} \mathrm{C}$ and below water saturation were made with a humidified tandem differential mobility analyzer (HTDMA) (Brechtel and Kreidenweis 2000). Virtually no water uptake was measured below $93 \% R H_{w}$ for any of the untreated nanoparticles using the HTDMA device, which is consistent with the inability of the HTDMA to resolve, within uncertainties, the expected small amounts of water uptake that could be associated with the soluble material responsible for CCN activity. Nevertheless, the consequence for these studies is that the water uptake properties of the untreated particles at below water saturation are not completely characterized. We do not know if there was continuous water uptake from some lower relative humidity or if, instead, the soluble component possessed a deliquescence relative humidity well above $90 \%$. It is therefore not possible to infer the exact nature of the ice formation 
Table 1. The weight $\%$ of sulfuric acid deposited on the mineral particles determined using measured $S_{\text {crit }}$ and Köhler theory for solutecoated spheres. The corresponding number of monolayers of acid is included in parenthesis where spherical particles are assumed with uniform coverage.

\begin{tabular}{llll}
\hline \multirow{2}{*}{$\begin{array}{l}\text { Particle Diameter } \\
(\mathrm{nm})\end{array}$} & \multicolumn{3}{c}{$\mathrm{S}_{\text {crit }}(\%)$, Weight fraction $\mathrm{H}_{2} \mathrm{SO}_{4}$ (monolayers $\mathrm{H}_{2} \mathrm{SO}_{4}$ ) } \\
$\mathrm{Al}_{2} \mathrm{O}_{3}$ & $3 \mathrm{Al}_{2} \mathrm{O}_{3}: 2 \mathrm{SiO}_{2}$ & $\mathrm{Fe}_{2} \mathrm{O}_{3}$ \\
\hline 100 & $0.43,0.051(4.6)$ & $0.41,0.070(5.0)$ & $0.41,0.045(5.3)$ \\
200 & $0.28,0.016(2.9)$ & $0.26,0.023(3.3)$ & $0.18,0.030(7.1)$ \\
\hline
\end{tabular}

mechanism for untreated particles, whether it is deposition nucleation or condensation freezing. Nevertheless, the acid coating process assured condensation freezing as the mechanism in the treated case.

HTDMA measurements of water uptake by the Asian dust particles at $85 \% R H_{w}$ gave hygroscopic growth factors $\left(D_{\text {wet }} / D_{\text {dry }}\right)$ of $1.155,1.125$ and 1.05 for 50,100 and $200 \mathrm{~nm}$ particles, respectively. These results indicated that the particles contained some soluble matter and that the smaller 50 and $100 \mathrm{~nm}$ particles contained relatively more soluble matter than the larger $200 \mathrm{~nm}$ particles. Particle concentrations were insufficient for accurately determining $\mathrm{CCN}$ activity for the natural dust sample. Nevertheless, assuming sulfuric acid as the soluble species for estimating soluble mass fraction via Köhler theory, soluble weight percents of about 5, 4, and $1.5 \%$ were inferred for 50,100 and $200 \mathrm{~nm}$ particles, respectively. Since these particles appeared to be internally mixed and capable of condensation, additional treatment with sulfuric acid was not performed. A consequence was also that the representativeness of the generated aerosol compared to the original natural dust sample was not known and remains as a precaution in applying the ice nucleation results presented in Sect. 3.3. Effective dry generation of these particles was not possible due to the very small mass $(2 \mathrm{~g})$ of total sample available for experimentation. Nevertheless, transmission electron microscopy analyses of the generated particles, such as those shown in the images in Fig. 2, indicated that all sizes possessed elemental signatures (especially $\mathrm{Si}, \mathrm{Al}$, and $\mathrm{Fe}$ ) that are quite similar to mineral dust particles detected as atmospheric ice nuclei (e.g., DeMott et al., 2003). It is also apparent from Fig. 2 that the natural particles did not possess the aggregate morphology of the manufactured surrogates.

\subsection{Continuous flow diffusion chamber}

The laboratory continuous-flow diffusion chamber (CFDC) used in these experiments enables real-time measurements of IN concentrations at controlled temperatures and humidities from a continuous stream of aerosol. The laboratory CFDC is the same instrument used previously to characterize homogeneous freezing by sulfuric acid/water (Chen et al., 2000) and pure dicarboxylic acid (Prenni et al., 2001) aerosols and is a modified version of the design described in
Table 2. Vapor pressure relations used for supersaturation calculations.

\begin{tabular}{ll}
\hline Water: & $e_{s w}[\mathrm{mb}]=6.1378 \exp \left(22.542\left(T\left[{ }^{\circ} \mathrm{C}\right] /\left(T\left[{ }^{\circ} \mathrm{C}\right]+273.48\right)\right)\right)$ \\
Ice: & $e_{s i}[\mathrm{mb}]=6.1378 \exp \left(17.9662\left(T\left[{ }^{\circ} \mathrm{C}\right] /\left(T\left[{ }^{\circ} \mathrm{C}\right]+247.15\right)\right)\right)$ \\
\hline
\end{tabular}

detail by Rogers (1988) and Rogers et al. (2001). The primary component of the CFDC is the vertically-oriented flow chamber, which consists of two concentric ice-coated cylinders, $1.5 \mathrm{~m}$ long, that are held at different temperatures to process particles at a calculated supersaturation with respect to ice within the annular region. For these experiments, the chamber was operated between $-45^{\circ}$ and $-60^{\circ} \mathrm{C}$ and from ice saturation into the water supersaturation regime. A preconditioner (Chen et al., 2000) was used to cool sample air to as low as $-30^{\circ} \mathrm{C}$ in order to reduce temperature contrasts before air enters the CFDC inlet manifold, which directs the sample flow ( $\sim 1.2$ liters per minute) into the center of the annulus where it merges with and is surrounded by two equal sheath flow lamina of particle-free air $(\sim 12$ liters per minute in total). At the chamber exit all flow passes through an optical particle counter (OPC, Climet Model 7350A). Ice crystals that are nucleated in the CFDC are detected by their growth to relatively large sizes $(>2 \mu \mathrm{m})$ compared to wet aerosol particles in equilibrium with the relative humidity conditions.

In the results that follow, ice formation in experiments is referenced primarily to the temperature and $R H_{i}$ conditions at which $1 \%$ of the particles activate as ice nuclei during the instrument residence time, which was 10 to $13 \mathrm{~s}$ for this study. Ice fraction activated is determined by comparing the ice crystal count to a total sample particle count as indicated by simultaneous measurements with the $\mathrm{CNC}$ and correction for particle losses through the instrument. Ice relative humidity is determined from the calculated water relative humidity and temperature at the aerosol lamina location in the CFDC, as described in Rogers (1988). Vapor pressure equations used for CFDC calculations are selected from Buck (1981), and are given in Table 2. We note that alternate expressions for the vapor pressure of water over ice and over supercooled liquid exist; these will yield different calculated values of ice supersaturation. The values of $R H_{\text {ice }}$ presented 

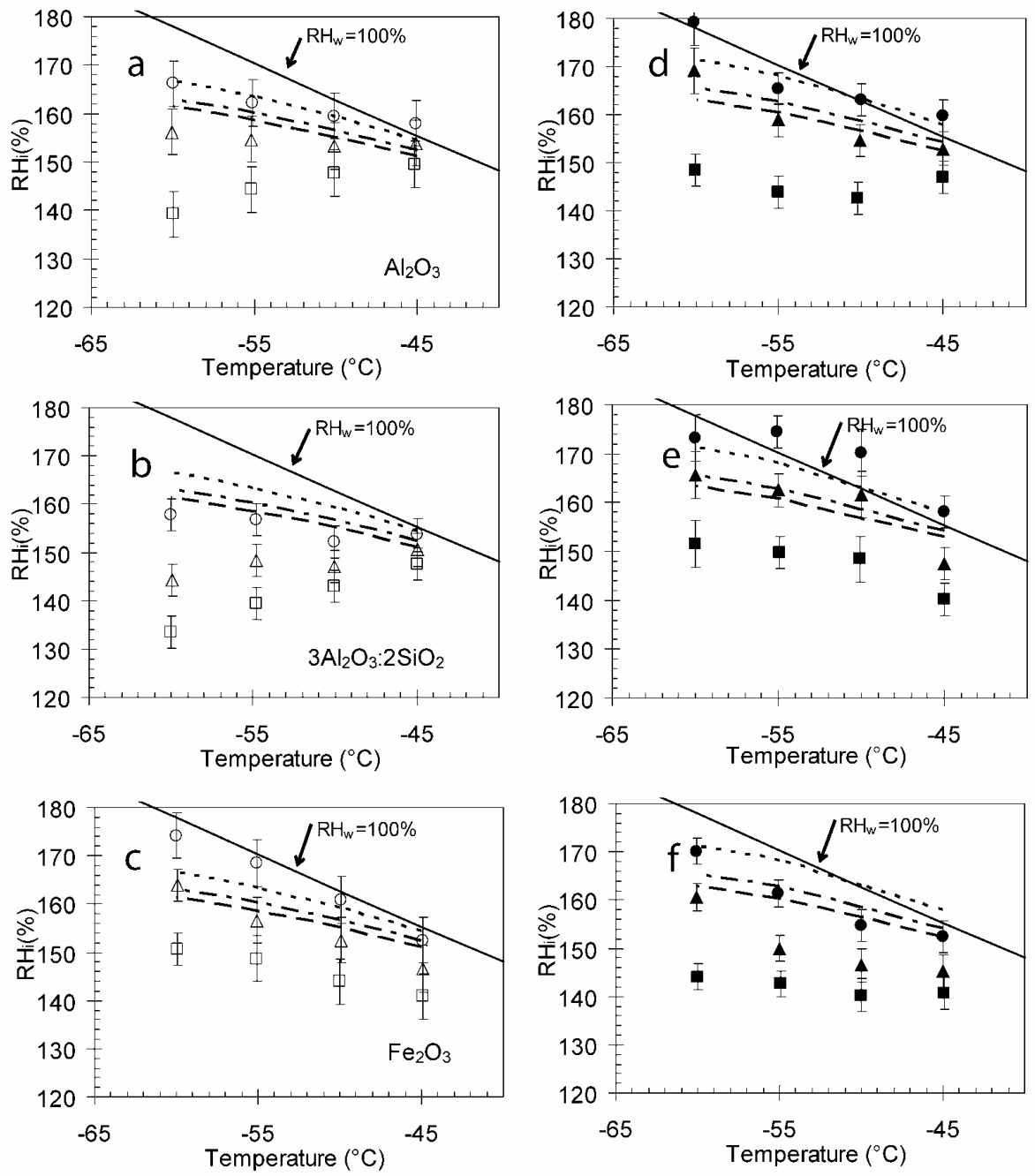

Fig. 4. The CFDC conditions for formation of ice on $1 \%$ of aluminum oxide (a, d), alumina-silicate (b, e) and iron oxide particles (c, f). Data for untreated particles are in the left panels and $\mathrm{H}_{2} \mathrm{SO}_{4}$-coated particles in the right panels. Data are presented for $50 \mathrm{~nm}$ (circles), 100 $\mathrm{nm}$ (triangles), and $200 \mathrm{~nm}$ (squares) aerosol particles. For comparison predicted homogeneous freezing conditions for pure $\mathrm{H}_{2} \mathrm{SO}_{4}$ particles (Chen et al., 2000) are denoted by curves in the left panels for $50 \mathrm{~nm}$ (dotted), $100 \mathrm{~nm}$ (dash-dot) and $200 \mathrm{~nm}$ (dashed) particles. The same curves in the right panels denote the predicted conditions for homogeneously freezing the $\mathrm{H}_{2} \mathrm{SO}_{4}-\mathrm{H}_{2} \mathrm{O}$ coatings, using data from Table 1 and an inferred initial $\mathrm{H}_{2} \mathrm{SO}_{4}$ content of 3.5 weight $\%$ on all $50 \mathrm{~nm}$ treated particles. A line for $R H_{w}=100 \%$ (water saturation) is included.

in this paper can be adjusted for alternate expressions using the information in Table 2.

\section{Ice nucleation results}

The size-resolved ice nucleation results for 50, 100 and $200 \mathrm{~nm}$ aluminum oxide, alumina-silicate and iron oxide particles are indicated respectively in Figs. $4 \mathrm{a}$ to $\mathrm{c}$ (without $\mathrm{H}_{2} \mathrm{SO}_{4}$ coatings) and Figs. $4 \mathrm{~d}$ to $\mathrm{f}$ (with $\mathrm{H}_{2} \mathrm{SO}_{4}$ coatings). Data points represent the $1 \%$ ice activation conditions for averages of 1 to 3 experiments and error bars represent the 95\% confidence intervals of these averages based on a pooled standard deviation of $2.83 \% R H_{i}$ and using a t-statistic with
45 degrees of freedom (size of the experimental data set). Pooled standard deviation was used as a means to mitigate the need otherwise for a very large $(>20)$ number of experiments for each aerosol system at each set of processing conditions. Ice formation results for untreated and coated commercial dust samples are also summarized in Table 4.

\subsection{Untreated mineral particles}

The appearance of ice formation below water saturation conditions (Figs. 4a to c) suggests that all of the untreated insoluble particle types possess apparent heterogeneous ice nucleation ability at upper tropospheric temperatures. Also included for comparison in Figs. 4a to $\mathrm{c}$ are curves representing 
Table 3. Ice nucleation results $\left(\% R H_{i}\right)$ for $1 \%$ freezing of pure (untreated) dust particles summarized as a function of particle type, size and temperature.

\begin{tabular}{llllllllll}
\hline & $\mathrm{Al}_{2} \mathrm{O}_{3}$ & & \multicolumn{5}{c}{$3 \mathrm{Al}_{2} \mathrm{O}_{3}: 2 \mathrm{SiO}_{2}$} & \multicolumn{5}{c}{$\mathrm{Fe}_{2} \mathrm{O}_{3}$} \\
\hline Temp & $50 \mathrm{~nm}$ & $100 \mathrm{~nm}$ & $200 \mathrm{~nm}$ & $50 \mathrm{~nm}$ & $100 \mathrm{~nm}$ & $200 \mathrm{~nm}$ & $50 \mathrm{~nm}$ & $100 \mathrm{~nm}$ & $200 \mathrm{~nm}$ \\
\hline$-45^{\circ} \mathrm{C}$ & 158.0 & 153.9 & 149.5 & 147.5 & 150.6 & 147.5 & 152.5 & 146.6 & 140.9 \\
& \pm 4.8 & \pm 4.8 & \pm 4.8 & \pm 4.8 & \pm 4.8 & \pm 4.8 & \pm 4.8 & \pm 4.8 & \pm 4.8 \\
$-50^{\circ} \mathrm{C}$ & 159.5 & 153.3 & 147.7 & 142.9 & 147.1 & 142.9 & 160.9 & 152.5 & 143.9 \\
& \pm 4.8 & \pm 4.8 & \pm 4.8 & \pm 4.8 & \pm 4.8 & \pm 4.8 & \pm 4.8 & \pm 4.8 & \pm 4.8 \\
$-55^{\circ} \mathrm{C}$ & 162.2 & 154.7 & 144.3 & 139.4 & 148.4 & 139.4 & 168.5 & 156.6 & 148.7 \\
& \pm 4.8 & \pm 4.8 & \pm 4.8 & \pm 3.4 & \pm 3.4 & \pm 3.4 & \pm 4.8 & \pm 4.8 & \pm 4.8 \\
$-60^{\circ} \mathrm{C}$ & 166.2 & 156.2 & 139.3 & 133.6 & 144.2 & 133.6 & 174.2 & 163.9 & 150.6 \\
& \pm 4.8 & \pm 4.8 & \pm 4.8 & \pm 3.4 & \pm 3.4 & \pm 3.4 & \pm 4.8 & \pm 3.4 & \pm 3.4 \\
\hline
\end{tabular}

Table 4. Ice nucleation results $\left(\% R H_{i}\right)$ for $1 \%$ freezing of coated dust particles summarized as a function of particle type, size and temperature.

\begin{tabular}{llllllllll}
\hline & $\mathrm{Al}_{2} \mathrm{O}_{3}\left(+\mathrm{H}_{2} \mathrm{SO}_{4}\right)$ & \multicolumn{3}{c}{$3 \mathrm{Al}_{2} \mathrm{O}_{3}: 2 \mathrm{SiO}_{2}\left(+\mathrm{H}_{2} \mathrm{SO}_{4}\right)$} & \multicolumn{3}{c}{$\mathrm{Fe}_{2} \mathrm{O}_{3}\left(+\mathrm{H}_{2} \mathrm{SO}_{4}\right)$} \\
\hline $\mathrm{Temp}$ & $50 \mathrm{~nm}$ & $100 \mathrm{~nm}$ & $200 \mathrm{~nm}$ & $50 \mathrm{~nm}$ & $100 \mathrm{~nm}$ & $200 \mathrm{~nm}$ & $50 \mathrm{~nm}$ & $100 \mathrm{~nm}$ & $200 \mathrm{~nm}$ \\
\hline$-45^{\circ} \mathrm{C}$ & 159.8 & 152.9 & 146.8 & 158.1 & 147.5 & 140.2 & 152.4 & 145.3 & 140.6 \\
& \pm 3.4 & \pm 3.4 & \pm 3.4 & \pm 3.4 & \pm 3.4 & \pm 3.4 & \pm 3.4 & \pm 3.4 & \pm 3.4 \\
$-50^{\circ} \mathrm{C}$ & 163.0 & 154.7 & 142.6 & 170.1 & 161.5 & 148.4 & 154.7 & 146.5 & 140.3 \\
& \pm 3.4 & \pm 3.4 & \pm 3.4 & \pm 4.8 & \pm 4.8 & \pm 4.8 & \pm 3.4 & \pm 3.4 & \pm 3.4 \\
$-55^{\circ} \mathrm{C}$ & 165.4 & 158.8 & 143.9 & 174.4 & 162.5 & 149.8 & 161.4 & 150.0 & 142.6 \\
& \pm 3.4 & \pm 3.4 & \pm 3.4 & \pm 3.4 & \pm 3.4 & \pm 3.4 & \pm 2.7 & \pm 2.7 & \pm 2.7 \\
$-60^{\circ} \mathrm{C}$ & 179.2 & 169.1 & 148.4 & 173.2 & 165.7 & 151.4 & 170.1 & 160.6 & 144.1 \\
& \pm 4.8 & \pm 4.8 & \pm 3.4 & \pm 4.8 & \pm 4.8 & \pm 4.8 & \pm 2.7 & \pm 2.7 & \pm 2.7 \\
\hline
\end{tabular}

homogeneous freezing conditions for pure sulfuric acid particles of the same sizes as the mineral dust particles, based upon data from Chen et al. (2000). This comparison emphasizes the conditions where heterogeneous nucleation by the relatively pure mineral particles could effectively compete with homogeneous ice formation in sulfate-water particles in the atmosphere. A few general conclusions are apparent. First, all three particle types were as effective or were more effective at initiating ice formation under upper tropospheric conditions, as compared with homogeneous freezing of pure sulfate particles of similar sizes. These differences are statistically significant at greater than the $95 \%$ confidence level in nearly $70 \%$ of the untreated mineral particle experiments, without consideration of particle size and temperature. Secondly, the apparent heterogeneous ice nucleating ability of the mineral particles, as indicated by the lowering of ice supersaturation for ice formation compared to the value at water saturation, becomes more effective at lower temperatures and larger particle sizes. The nature of ice nu- cleation varied among the different particle types, as indicted by different trends of conditions of $R H_{i}$ versus temperature $\left(\Delta R H_{i} / \Delta T\right)$ required for $1 \%$ ice formation. The $\Delta R H_{i} / \Delta T$ values were zero or positive for alumina-silicate particles of all sizes larger than $50 \mathrm{~nm}$ and these particles were the most effective of the untreated particles at initiating ice formation at lower temperatures. Results for untreated aluminum oxide particles displayed a similar positively valued trend in $\Delta R H_{i} / \Delta T$ as particle size increased. In contrast, iron oxide particles maintained a negative $\Delta R H_{i} / \Delta T$ at all particle sizes examined, but were the most effective of the manufactured particles as ice nuclei at $-45^{\circ} \mathrm{C}$. The differences among the three particle types may relate to their fundamental properties for catalyzing ice formation, but may also be affected by the small amounts of soluble matter contamination in the particles as suggested by the $\mathrm{CCN}$ measurements for untreated particles. As already discussed, the presence of some apparent soluble matter ( $\sim 0.5 \%$ by mass $)$ in the untreated particles complicates discerning the ice nucleation 
Table 5. Ice nucleation results $\left(\% R H_{i}\right)$ for $1 \%$ freezing of reference Asian dust particles summarized as a function of particle size and temperature.

\begin{tabular}{llll}
\hline \multicolumn{4}{l}{ Reference Asian Dust } \\
\hline Temp & $50 \mathrm{~nm}$ & $100 \mathrm{~nm}$ & $200 \mathrm{~nm}$ \\
\hline$-45^{\circ} \mathrm{C}$ & $172.4 \pm 4.8$ & $154.6 \pm 4.8$ & $135.9 \pm 4.8$ \\
$-50^{\circ} \mathrm{C}$ & $170.3 \pm 4.8$ & $154.7 \pm 4.8$ & $133.7 \pm 4.8$ \\
$-55^{\circ} \mathrm{C}$ & $163.2 \pm 3.4$ & $157.5 \pm 3.4$ & $134.3 \pm 3.4$ \\
$-60^{\circ} \mathrm{C}$ & $161.0 \pm 4.8$ & $156.2 \pm 4.8$ & $136.1 \pm 4.8$ \\
\hline
\end{tabular}

mechanism as deposition or condensation freezing for these particles.

\section{2 $\mathrm{H}_{2} \mathrm{SO}_{4}$-treated mineral particles}

The size-resolved results for $\mathrm{H}_{2} \mathrm{SO}_{4}$-treated 50, 100 and $200 \mathrm{~nm}$ aluminum oxide, alumina-silicate and iron oxide particles are indicated respectively in Figs. 4d, e and f. The treatment was intended to promote condensation prior to ice nucleation, under the assumption that sulfuric acid coatings exceeding more than a few monolayers were sufficient to assure that the heterogeneous ice formation mechanism would be condensation freezing. We then classified each result for treated particles, compared with the analogous result for the untreated case, as enhancing, hindering, or leaving unaltered the ice-nucleating activity of each particle type and size, using a $95 \%$ confidence level for ascribing statistical significance. Aluminum oxide particles of all sizes showed no statistical difference in ice formation conditions whether treated or untreated, except at $-60^{\circ} \mathrm{C}$ where the treated particles required higher $R H_{i}$ for ice formation. Alumina silicate particles of all sizes were more effective in the untreated state, at all temperatures below $-50^{\circ} \mathrm{C}$ (statistically significant in all but one case). In contrast, iron oxide particles appeared modestly more effective when coated with sulfuric acid and this result was statistically significant for half of the combinations of tested size and temperature.

Included for comparison in Figs. 4d-f are curves representing homogeneous freezing of the sulfuric acid-water component of the different sized particles based on the measured weight percent of acid, calculation of equilibrium composition versus $R H$ using Köhler theory and the freezing rates as a function of $\mathrm{H}_{2} \mathrm{SO}_{4}-\mathrm{H}_{2} \mathrm{O}$ composition from Chen et al. (2000). All of the $200 \mathrm{~nm}$ treated particles nucleated ice at lower $R H_{i}$ than the conditions for which homogeneous freezing of the liquid component of the particles was predicted, significant at a $99.5 \%$ confidence level. For $100-$ and 50-nm particles, the $R H_{i}$ points of apparent heterogeneous freezing nucleation for aluminum oxide and alumina-silicate particles are typically lower but indistinguishable, within experimental uncertainty, from the condition that would lead to

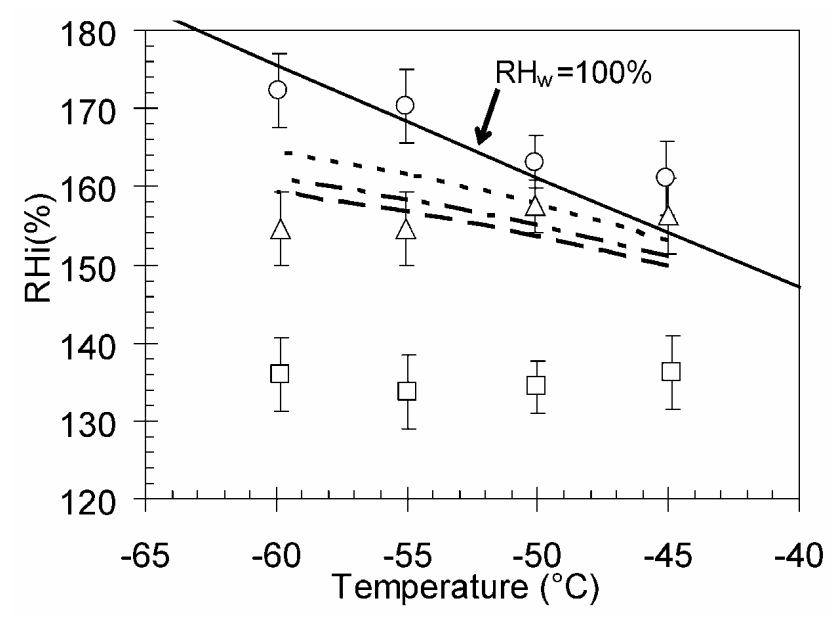

Fig. 5. As in Fig. 4, but showing CFDC conditions for the formation of ice on $1 \%$ of particles from the sample of resuspended Asian dust. The homogeneous freezing curves are for pure sulfuric acid particles.

homogeneous freezing of the acid-water solution in the particles. Only the treated iron oxide particles nucleated ice at a statistically-lower $R H_{i}$ than that at which the liquid shell was predicted to freeze homogeneously.

\subsection{Reference Asian mineral dust particles}

Measurements of the ice nucleating activity of selected sizes of the resuspended reference Asian dust sample are shown in Fig. 5 and Table 5. The soluble species content estimates given in Sect. 2 indicated that the smaller 50 and $100 \mathrm{~nm}$ generated particles contained relatively more soluble matter than the larger $200 \mathrm{~nm}$ particles. This variation in soluble matter content was associated with a pronounced size separation in ice nucleation conditions, especially in the size step between 100 and $200 \mathrm{~nm}$. The $100 \mathrm{~nm}$ Asian dust particles did not nucleate ice at conditions substantially different from those required to homogeneously freeze $100 \mathrm{~nm}$ sulfuric acid particles, but the $200 \mathrm{~nm}$ natural mineral dust particles were very effective ice nuclei, initiating ice formation at ice relative humidities more than $5 \%$ below those of any of the manufactured mineral particles studied here. Interestingly, to first order, heterogeneous ice nucleation on these particles below water saturation seems to depend only on particle size and ice relative humidity. This result is similar in form to results reported for clay minerals in earlier studies using static diffusion chambers to process 0.5 to $3 \mu \mathrm{m}$ diameter particles collected on filters (e.g., Roberts and Hallett, 1968).

\subsection{Summary of ice nucleation results}

Figure 6 summarizes results for $200 \mathrm{~nm}$ particles of all particle types studied in this work. Figure $6 \mathrm{a}$ is a summary of the ice nucleation conditions for untreated particles. Also 
included are curves denoting the homogeneous freezing conditions for $200 \mathrm{~nm} \mathrm{H}_{2} \mathrm{SO}_{4}$ particles (Chen et al., 2000) and the $R H_{i}$ inferred for the onset of continental cirrus cloud formation based on observations by Heymsfield and Milosevich (1995). The conditions inferred for cirrus formation by Heymsfield and Milosevich (1995) bound the minimum $R H_{i}$ conditions required for upper tropospheric cloud formation in observational studies of cirrus over the continental United States during the FIRE II (First ISCCP (International Cloud Climatology Project) Regional Experiment) program in spring 1991. Since that study was conducted during springtime, the peak season for Asian dust transport to the United States (VanCuren and Cahill, 2002), these observations are most likely to have captured potential effects of heterogeneous nucleation by dust particles on cirrus clouds. Studies of cirrus in the INCA (INterhemispheric differences in Cirrus properties from Anthropogenic emissions) program found that, although homogeneous freezing likely dominates in most cirrus situations, evidence from observational data (Ström et al., 2003) and process modeling studies (Haag et al., 2003) suggests that a modest population of IN (concentrations somewhat less than $0.01 \mathrm{~cm}^{-3}$ ) activating near $130 \%$ $R H$ influences the onset of freezing in cirrus in parts of the polluted Northern Hemisphere. Freezing-onset $R H$ conditions were higher in less-polluted Southern Hemisphere sampling locales.

The $200 \mathrm{~nm}$ aluminum oxide and alumina-silicate particle activation conditions trend in the same direction as the conditions reported by Heymsfield and Milosevich. The slope of $200 \mathrm{~nm}$ iron oxide particle activation conditions is similar to that for homogeneous freezing of sulfuric acid solutions.

Figure $6 \mathrm{~b}$ summarizes the freezing conditions for the treated $200 \mathrm{~nm}$ aluminum oxide, alumina-silicate and iron oxide minerals. The heterogeneous freezing conditions of these metal oxide particles come much closer to the onset conditions for cirrus formation suggested by Heymsfield and Milosevich than do previous results for homogenous freezing of sulfate particles measured with the CFDC instrument. The ice nucleation conditions for the $200 \mathrm{~nm}$ Asian dust particles are also included in Fig. 6b, under the assumption that the measured water uptake properties inferred from the HTDMA would favor a condensation freezing mechanism. Figure $6 \mathrm{~b}$ emphasizes that these natural dust particles nucleate ice at $R H_{i}$ conditions that are 5-9\% lower than the treated surrogate mineral particles. To first order, all of the 200-nm treated particles and the 200-nm Asian dust samples nucleated ice at nearly constant ice relative humidity conditions. The onset relative humidity for ice nucleation of the $200 \mathrm{~nm}$ Asian dust particles is approximately the same as the ice relative humidity $\left(130 \% R H_{i}\right)$ found in the INCA measurements to characterize apparent ambient heterogeneous ice nuclei. This agreement may be fortuitous since the observed strong size dependence of ice nucleation would suggest even lower $R H_{i}$ activation for larger suspended particles, a fraction of which will be subject to long-range transport.
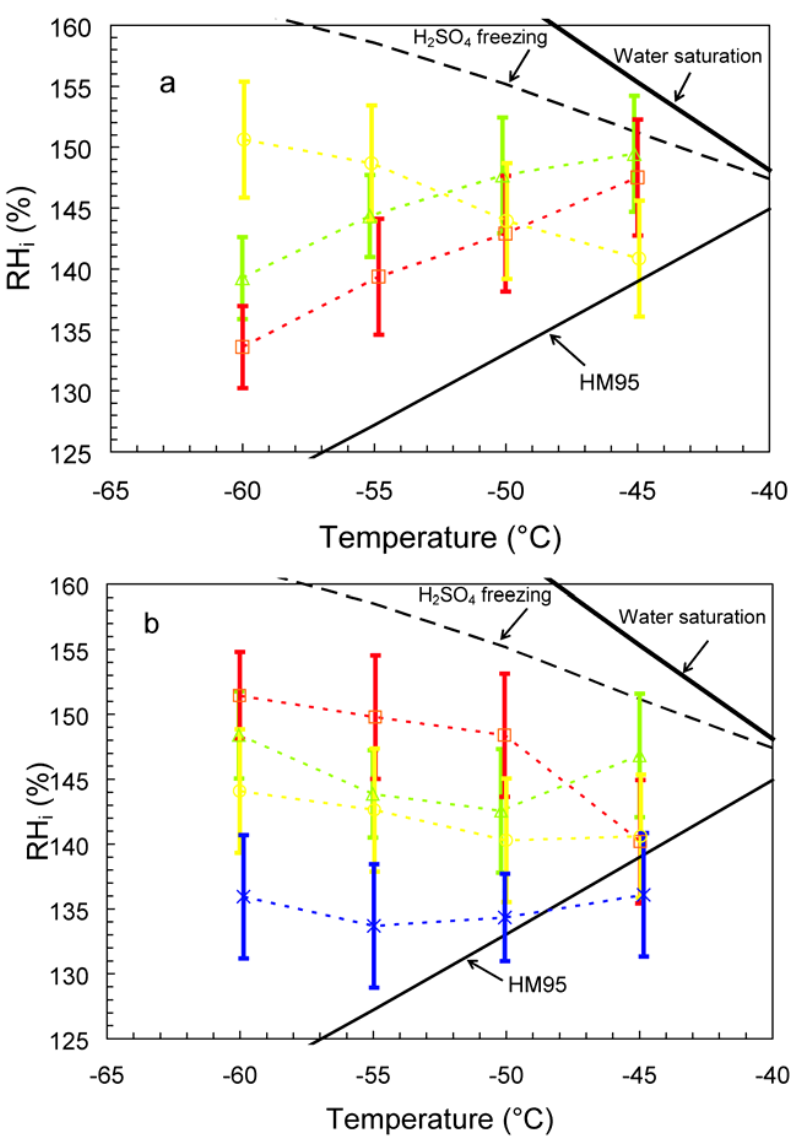

Fig. 6. The CFDC conditions for formation of ice on $1 \%$ of $200 \mathrm{~nm}$ untreated particles (a) and the treated aerosols along with the Asian dust aerosols (b). Respective core particle types are aluminum oxide (green), alumina-silicate (red), iron oxide (yellow) and Asian dust (blue). A line summarizing the relative humidity required for cirrus formation (HM95) derived in a field study (FIRE-II) by Heymsfield and Miloshevich (1995) is also shown. Other lines indicate conditions for homogeneous freezing of $200 \mathrm{~nm}$ pure sulfate particles based on CFDC measurements by Chen et al. (2000) and saturation with respect to water.

It is interesting that sulfuric acid coatings largely inhibited the innate ice nucleating capability of the aluminasilicate particles. These particles are specified by the manufacturer as having amorphous surfaces, in contrast to the oxides which are crystalline. Bassett et al. (1970) suggested a heterogeneous freezing mechanism for such surfaces that involves adsorption of water at discrete locations on a hydrophobic surface, where the advantage of a hydrophobic surface is that it promotes cluster formations that more easily stabilize and form ice than a liquid-like layer of water. This suggests that a partially hydrophilic substrate, which is an effective ice-nucleating agent in water vapor, is less effective when the surface of the substrate is covered by a liquid layer. 


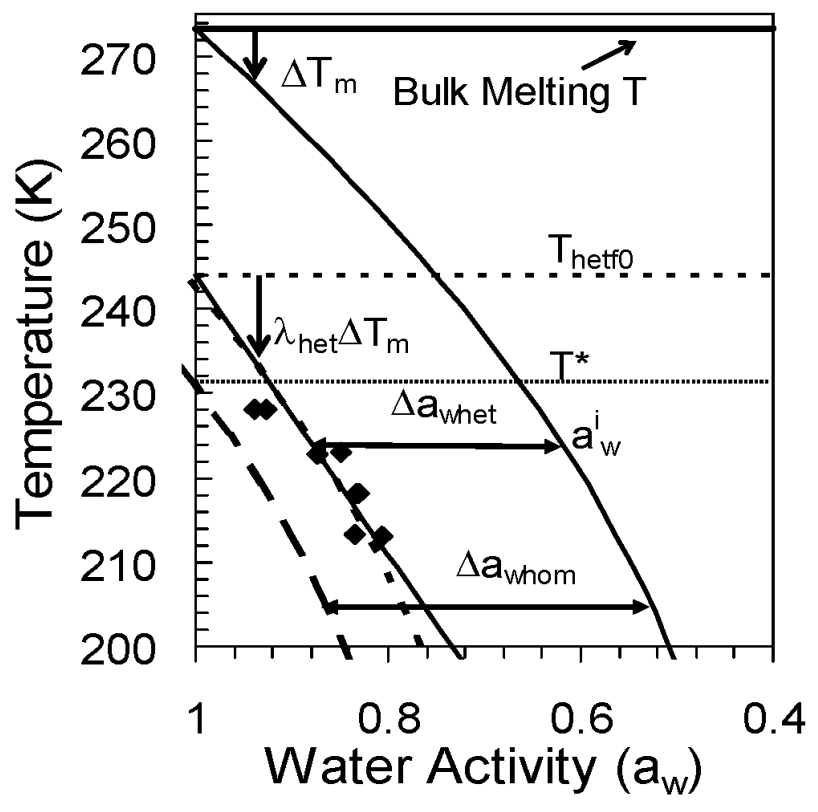

Fig. 7. An example of data for heterogeneous freezing temperature versus water activity, in this case for $\mathrm{Al}_{2} \mathrm{O}_{3}$ particles. The diamonds represent the conditions for freezing $1 \%$ of $200 \mathrm{~nm}$ core particles (coated with sulfuric acid) in the CFDC residence time. The curve $a_{w}^{i}$ denotes the activity of water in a bulk solution in equilibrium with ice, based on Buck (1981), and the intersecting solid horizontal line is the bulk freezing temperature for pure water $(273.15 \mathrm{~K})$. Arrows represent the melting point depression for pure water $\left(\Delta T_{m}\right)$ and the nucleation point depression for diluted sulfuric acid with a mineral immersion $\left(\lambda_{\text {het }} \Delta T_{m}\right)$. The thin solid curve represents the equation $T_{\text {hetf }}=244-1.6 \Delta T_{m}$ and horizontal dashed line represents the temperature at which pure water with a mineral immersion is expected to freeze with the same nucleation rate as solution drops ( $\left.T_{\text {hetf } 0}\right)$. The short-dashed curve represents $a_{w}^{i}$ shifted by $\Delta a_{\text {whet }}=0.25$. The long dashed curve represents predicted homogeneous freezing conditions of the solution component and $\mathrm{T}^{*}$ is the effective homogeneous freezing temperature (see text).

Overall, the range of cirrus formation conditions by the treated and untreated mineral oxide particles span the full range of cirrus formation conditions suggested in some other atmospheric studies (e.g., Jensen et al., 2001).

\section{Quantifying heterogeneous freezing by mineral dust/sulfate particles}

Absent a first principle understanding of heterogeneous ice nucleation for atmospheric aerosols, a number of parametric approaches have been used to represent these processes in numerical modeling studies. Two approaches used for quantifying homogeneous freezing nucleation are examined here for relevance to parameterization of heterogeneous freezing nucleation (treated particle results). In addition, nucleation rates are derived, as these are useful for parameterization de- velopment and for evaluating the suitability of classical nucleation theory for interpreting experimental results. Parameterization of the results for untreated particle types will not be considered in this paper since the ice formation mechanism is not clearly defined.

4.1 Freezing point depression and water activity parameterizations

Solutes have the effect of lowering the equilibrium melting point of a solution. Sassen and Dodd (1988) formulated a parameterization of homogeneous freezing of solution droplets at cirrus condition, based on earlier observations that the median homogeneous freezing temperatures of emulsified drops were depressed by solutes to an even greater extent than the lowering of the melting point, so that

$\Delta T_{h f}=\lambda \Delta T_{m}$

where $\Delta T_{h f}$ is the homogeneous freezing point depression and $\Delta T_{m}$ is the melting point depression for a specific salt concentration. Sassen and Dodd (1988) also proposed that the proportionality constant $\lambda$ is valid at temperatures other than the temperatures at which drops freeze very rapidly and so could form the basis of a parameterization valid over a continuum of nucleation rates. Thus, they defined an effective homogeneous freezing temperature $T^{*}$ as,

$T^{*}=T+\lambda \Delta T_{m}$

where $T$ is the actual temperature of the solution drops. Using $T^{*}$ instead of $T$ in a temperature dependent theoretical or parametric expression for the volumetric nucleation rate of pure water then permits estimation of the volumetric nucleation rate of solution drops $\left(J_{h f}\right)$ as a function of both temperature and composition (DeMott, 2002). $T^{*}$ is thus understood as the temperature at which a solution droplet $\left(a_{w}<1\right)$ achieves the same nucleation rate as a pure water droplet $\left(a_{w}=1\right)$ of the same size. For homogeneous nucleation of haze particles, $\lambda$ ranges from 1.4 to 2.2 for different solutions (DeMott, 2000). Sassen and Dodd proposed a $\lambda$ equal to 1.7 to characterize a wide range of solutes and Chen et al. (2000) confirmed values ranging from about 1.5 to 2 for sulfate aerosols.

DeMott (2002) also suggested that a similar parameterization might be used for heterogeneous freezing, such that $\Delta T_{\text {hetf }}$ replaces $\Delta T_{h f}$ in Eq. (1) and the heterogeneous freezing rate $\left(\mathrm{cm}^{-2} \mathrm{~s}^{-1}\right)$ is given by $J_{\text {hetf }}\left(T_{\text {hetf } 0}\right)$ where $J_{\text {hetf }}$ is the heterogeneous freezing rate and $T_{\text {hetfo }}$ is an effective heterogeneous freezing temperature akin to $T^{*}$. Thus,

$\Delta T_{\text {hetf }}=\lambda_{\text {het }} \Delta T_{m}$

and

$T_{\text {hetf } 0}=T+\lambda_{\text {het }} \Delta T_{m}$ 
Zuberi et al. (2002) found that $\lambda_{\text {het }}$ equal to 1.7 fit their median freezing temperature data for the heterogeneous nucleation of ice in 10 to $55 \mu \mathrm{m}$ aqueous $\left(\mathrm{NH}_{4}\right)_{2} \mathrm{SO}_{4}-\mathrm{H}_{2} 0$ particles containing kaolinite and montmorillonite powders. This suggests that perhaps $\lambda$ is insensitive to the fundamental nucleation process in solutions (e.g., $\lambda_{\text {het }}=\lambda$ ) and that $T_{\text {hetfo }}$ $\left(>T^{*}\right)$ primarily describes the role of the insoluble substrate, capturing the effect of size and insoluble particle composition. Thus, $T_{\text {hetfo }}$ is a variable parameter that depends on particle size, nucleation rate and the core particle type.

Koop et al. (2000) proposed that homogeneous freezing depends on solution droplet water activity $\left(a_{w}\right)$, such that the difference between $a_{w}$ and $a_{w}^{i}$, the water activity of the solution in equilibrium with ice, is constant for a given particle size:

$\Delta a_{w}=a_{w}-a_{w}^{i}$

Zuberi et al. (2002) obtained a reasonable fit when they tested whether this method could be applied to heterogeneous freezing of the mineral dust immersions in supermicron drops. We will term the differential water activity for heterogeneous nucleation, analogous to that for homogeneous freezing in Eq. (5), as $\Delta a_{\text {whet }}$.

The two parametric approaches are compared for data in this study in Fig. 7. This figure shows the heterogeneous freezing temperatures determined using the CFDC for 200$\mathrm{nm} \mathrm{H}_{2} \mathrm{SO}_{4}$-coated aluminum oxide particles, plotted against water activity. Water activity was determined using Köhler theory and using the measured $R H$ conditions, dry particle size and soluble content as inputs. The assumption of dropvapor equilibrium used in this calculation is probably most reasonable when ice formation occurs below 95\% $R H_{w}$. This discussion is therefore focused on results for treated 100 and $200 \mathrm{~nm}$ particles.

The thin solid curve in Fig. 7 indicates the best fit of the data to Eq. (4). The line is extrapolated to $a_{w}=1$ to estimate an intercept temperature $T_{\text {hetf } 0}$ as the temperature at which pure water particles with mineral dust immersions would freeze in the proportion measured (e.g., 1 in 100 particles freezing) in the CFDC residence time. The resulting best-fit equations for treated aluminum oxide, alumina-silicate and iron oxide are listed in Table 6 . Included under each equation is the square of the correlation coefficient relating the equation to the corresponding experimental data. Overall, Eq. (4) could be fit to describe the nucleation behavior of the treated $200 \mathrm{~nm}$ particles fairly well, with an average $r^{2}$ of 0.89 . The $100 \mathrm{~nm}$ particles could not be fit quite as well with the equations, with an average $r^{2}$ of 0.53 . For these investigations, the coefficient $\lambda_{\text {het }}$ ranges from 1.1 to 1.9 for solutions of $\mathrm{H}_{2} \mathrm{SO}_{4}$ on 100 and $200 \mathrm{~nm}$ aluminum oxide, alumina-silicate and iron oxide particles. The lowest correlation in these studies was for the $100 \mathrm{~nm}$ alumina-silicate particles $\left(r^{2}=0.37\right)$ where $\lambda_{\text {het }}=1.1$. Disregarding this point, the values for the coefficient $\lambda_{\text {het }}$ range from 1.4 to 1.9. This range agrees with

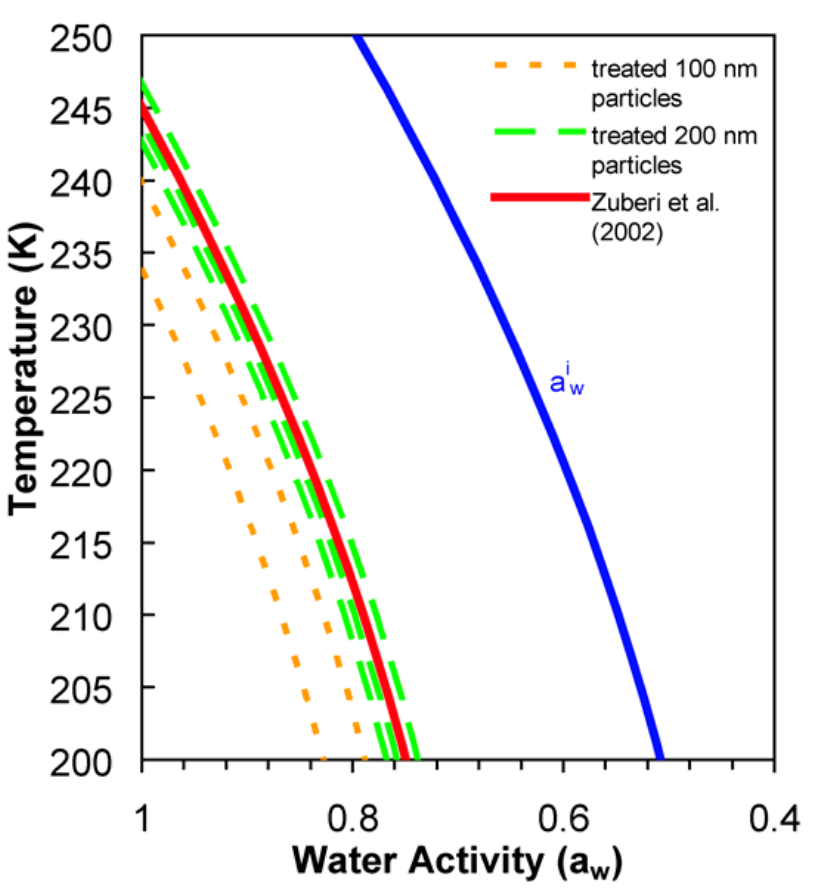

Fig. 8. Comparison of freezing data using line fits to constant $\Delta a_{\text {whet }}$. The thick solid line represents median freezing temperature results from Zuberi et al. (2002) for large koalinite and montmorillite inclusions in aqueous $\left(\mathrm{NH}_{4}\right)_{2} \mathrm{SO}_{4}$. The dotted (dashed) lines represent $1 \%$ freezing results from this study for $100 \mathrm{~nm}$ $(200 \mathrm{~nm})$ aluminum oxide, alumina-silicate and iron oxide particles with $\mathrm{H}_{2} \mathrm{SO}_{4}$ coatings. The different particle types are not distinguished so as to focus on general size effects.

the range that has been reported from homogeneous freezing investigations $(\lambda=1.4-2.2)$.

Results for $\Delta a_{\text {whet }}$ for treated aluminum oxide particles are plotted in Fig. 7 as the dashed curve, Included in the plots is the line for $a_{w}^{i}$ (Table 2). The corresponding $\Delta a_{\text {whet }}$ equations for treated aluminum oxide and the equations that were best fits to the treated alumina silicate and iron oxide data are listed in Table 6. Correlations between these curves and the experimental data are also listed. Equation (5) could be fit to describe the nucleation behavior of the treated $100 \mathrm{~nm}$ and $200 \mathrm{~nm}$ particles at least as well as Eq. (4). The $200 \mathrm{~nm}$ water activity fit had an average $r^{2}$ to the experimental data of 0.89 and the $100 \mathrm{~nm}$ particles had an average $r^{2}$ of 0.51 .

Figure 8 shows the constant $\Delta a_{\text {whet }}$ line fits for sizeresolved data for various compositions of treated particles in this study. For comparison, we also show a constant $\Delta a_{\text {whet }}$ line fit by Zuberi et al. (2002) to their data for heterogeneous nucleation of ice in aqueous $\left(\mathrm{NH}_{4}\right)_{2} \mathrm{SO}_{4}-\mathrm{H}_{2} \mathrm{O}$ particles containing kaolinite and montmorillonite. The data from this study approach the data from the Zuberi et al. (2002) study as the particles become larger. The mineral dust surface areas in the Zuberi et al. (2002) work are not well quantified, but were certainly representative of much larger particles than in 
Table 6. Comparison of the best fit equations for two methods, $T_{\text {hetf } 0}=T+\lambda$ het $\Delta T_{m}$ and $\Delta a_{\text {whet }}=a_{\text {whet }}-a_{w}^{i}$, used to describe heterogeneous freezing data ( $1 \%$ activation conditions) for treated 100 and $200 \mathrm{~nm}$ aluminum oxide, alumina silicate particles and treated 50,100 and $200 \mathrm{~nm}$ iron oxide particles. The correlation $r^{2}$ for each equation as compared to the experimental data set is in parentheses. The $\Delta a_{\text {whom }}$ values for homogeneous freezing are shown for reference. The contact parameter $(m)$ derived for a classical theory calculation of heterogeneous freezing (see text) is also listed.

\begin{tabular}{llllll}
\hline & $D(\mathrm{~nm})$ & $T_{\text {hetf }}\left(r^{2}\right)$ & $\Delta a_{\text {whet }}\left(r^{2}\right)$ & $\Delta a_{\text {whom }}\left(r^{2}\right)$ & $m$ \\
\hline Aluminium Oxide & 100 & $\begin{array}{l}234-1.5 \Delta T_{m} \\
(0.74)\end{array}$ & $\begin{array}{l}0.32 \\
(0.73)\end{array}$ & 0.331 & -0.90 \\
& 200 & $\begin{array}{l}244-1.6 \Delta T_{m} \\
(0.92)\end{array}$ & $\begin{array}{l}0.25 \\
(0.93)\end{array}$ & 0.328 & -0.15 \\
\hline Alumina Silicate & 100 & $\begin{array}{l}230-1.1 \Delta T_{m} \\
(0.37)\end{array}$ & $\begin{array}{l}0.32 \\
(0.33)\end{array}$ & 0.331 & \\
\cline { 2 - 6 } & 200 & $\begin{array}{l}247-1.9 \Delta T_{m} \\
(0.85)\end{array}$ & $\begin{array}{l}0.26 \\
(0.83)\end{array}$ & 0.328 & -0.30 \\
\hline Iron Oxide & 50 & $\begin{array}{l}233-1.4 \Delta T_{m} \\
(0.55)\end{array}$ & $\begin{array}{l}0.31 \\
(0.54)\end{array}$ & 0.334 & -0.30 \\
\cline { 2 - 6 } & 100 & $\begin{array}{l}238-1.4 \Delta T_{m} \\
(0.47)\end{array}$ & $\begin{array}{l}0.28 \\
(0.48)\end{array}$ & 0.331 & -0.10 \\
\cline { 2 - 6 } & 200 & $\begin{array}{l}244-1.4 \Delta T_{m} \\
(0.91)\end{array}$ & $\begin{array}{l}0.23 \\
(0.10)\end{array}$ & 0.328 & \\
\cline { 2 - 6 } & & & & & \\
\hline
\end{tabular}

the current study. However, the freezing condition used by Zuberi et al. (2002) was the median freezing temperature, in contrast to the $1 \%$ freezing level used in the current study. Higher freezing rates would tend to require higher water activity. Although a direct comparison between the two studies is not possible, the new data in this paper supports the application of the relation between heterogeneous freezing and water activity for soluble-species-coated mineral oxide and clay particles.

A general result apparent in Table 6 and Fig. 8, at least for particles as small as $200 \mathrm{~nm}$, is that $\Delta a_{\text {whet }}$ or alternately, $T_{\text {hetfo, }}$, are size dependent. It remains to be explored if the trend with particle size continues toward larger sizes, as this would be an important factor to consider in applying such results to atmospheric size distributions of mineral dust aerosols. A water-activity-based parameterization to utilize data of the type presented here has been described by Kärcher and Lohmann (2003). Fully quantifying the behaviors of mineral dust particles as ice nuclei for use in numerical modeling will entail determining the dependence of the inherent nucleation rates on particle size and composition over the entire range of supercooled temperatures.

\subsection{Nucleation rates}

Heterogeneous nucleation is thought to critically depend on the number of ice nucleation active sites, with the probability of a particle containing active sites increasing with particle surface area. Using the assumption that heterogeneous nucleation depends on the surface areas of the aerosol particles, the fraction of particles of class $i$ freezing is,

$F_{i}=1-\exp \left(J_{\text {hetf }} A_{i} \Delta t\right)$

where $J_{\text {hetf }}\left(\mathrm{cm}^{-2} \mathrm{~s}^{-1}\right)$ is the heterogeneous freezing rate of the particles and $A_{i}\left(\mathrm{~cm}^{2}\right)$ is the surface area of the core particle.

Hung et al. (2003) reported values of $J_{\text {hetf }}$ computed for polydisperse distributions of hematite (iron oxide) and corundum (aluminum oxide) core particles treated with $\left(\mathrm{NH}_{4}\right)_{2} \mathrm{SO}_{4}$. The core particles were generated using spray pyrolysis of aqueous metal salt solutions, the same basic process used to create the manufactured powders used in this study. Particles were coated with sulfuric acid in a similar manner as done in this work, and the coatings were then neutralized with excess $\mathrm{NH}_{3}(\mathrm{~g})$. Particle compositions and freezing onset were detected in an aerosol flow tube using infrared spectroscopy. Nucleation rates were determined by Hung et al. (2003) using an iterative procedure that involved guessing $J_{\text {hetf }}$ values in Eq. (6) and modeling ice formation 


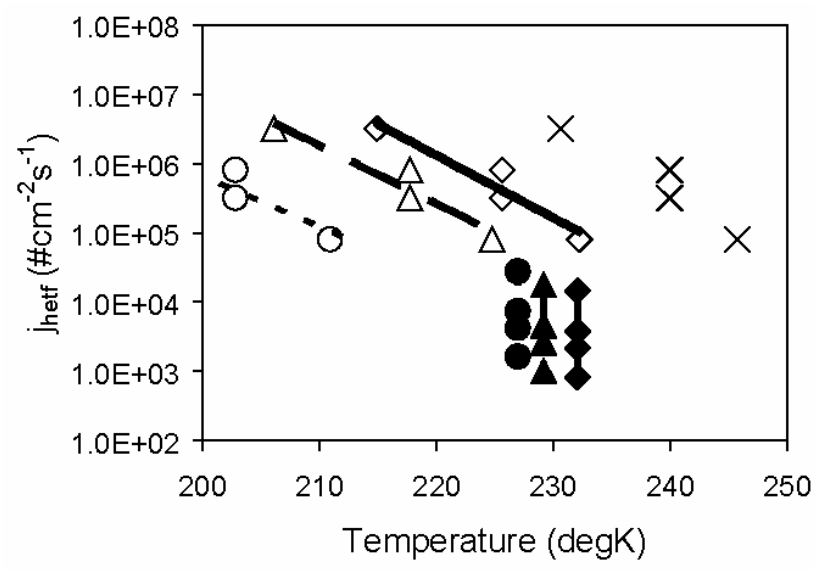

Fig. 9. Derived nucleation rates. Lines with open symbols represent lines of constant $a_{w}$ for 1.0 and $0.1 \%$ activation of 100 and $200 \mathrm{~nm}$ aluminum oxide particles treated with $\mathrm{H}_{2} \mathrm{SO}_{4}$. Lines with filled symbols represent data from Hung et al. (2003) for active fractions between 0.003 and $0.000003 \%$ of aluminum oxide particles treated with $\left(\mathrm{NH}_{4}\right)_{2} \mathrm{SO}_{4}$ and having mode diameters of 50, 120, 150 and $200 \mathrm{~nm}$. The different lines (exponential fits for current data) represent $a_{w}=0.91$ (solid) $a_{w}=0.87$ (dashed) and $a_{w}=0.79$ (dotted). Results for $a_{w}=1$, based on extrapolated intercepts from CFDC studies (as in Fig. 8) are given as crosses.

and growth in the experimental section of the flow tube until the ice mass inferred from calculation matched that inferred from the spectroscopic measurements. The particle composition associated with the frozen particles was inferred from a combination of spectroscopic measurement and numerical modeling of particle-size dependent composition.

Nucleation rate calculations were relatively straightforward for the data collected in the present study. The residence time of particles after initial adjustment to the conditions in the CFDC was approximately $10 \mathrm{~s}$. $A_{i}$ in Eq. (6) is computed assuming spherical particles where $A_{i}=\pi D_{i}^{2}$ and $D_{i}$ is the diameter of the mineral dust core. With $F_{i}, A_{i}$ and $\Delta t$ known, $J_{\text {hetf }}$ can be calculated in Eq. (6). Thus, for example, $1 \%$ activation conditions represent nominal heterogeneous nucleation rates of $1 \times 10^{-3}$ per particle per second or $1.3 \times 10^{7}, 3.2 \times 10^{6}$, and $8.0 \times 10^{5} \mathrm{~cm}^{-2} \mathrm{~s}^{-1}$ for $50-, 100-$ and 200-nm particles, respectively, assuming uniform nonporous surface area and spherical shape. Köhler theory was used to associate a composition and thus a water activity with each nucleation rate. Data for conditions where $\sim 0.1 \%$ of the particles activated were also used in this analysis to achieve a broader sense of the trends in nucleation rates. Uncertainties in these nucleation rate calculations are present through the residence time and surface area terms. The residence time uncertainty is a one-way uncertainty because ice crystals must grow to larger than $2 \mu \mathrm{m}$ in order to contribute to the measured nucleation signal. Ice crystal growth calculations for the CFDC (not presented) suggest that the $10 \mathrm{~s}$ time could be an overestimate by up to a factor of 2 in some cases,

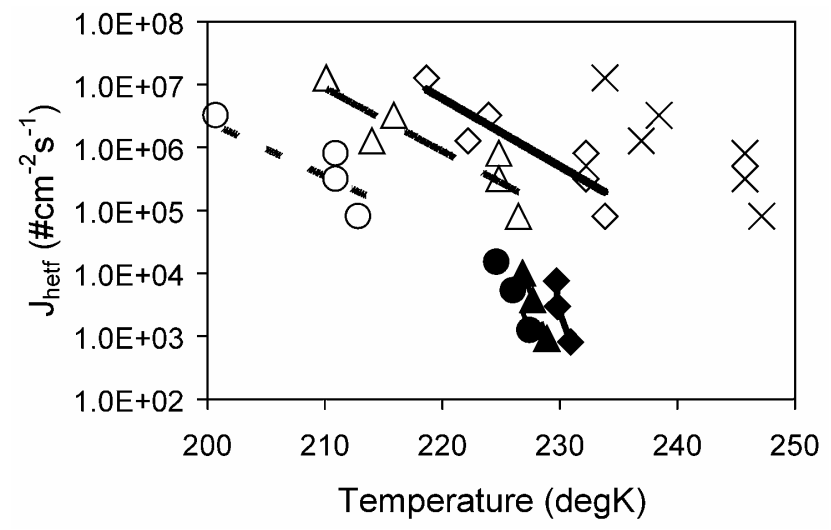

Fig. 10. As in Fig. 9, but for iron oxide particles treated with $\mathrm{H}_{2} \mathrm{SO}_{4}$. Mode diameters of coated iron oxide particles from Hung et al. (2003) are 80, 150 and $250 \mathrm{~nm}$.

leading to a direct underestimate of $J_{\text {hetf }}$ by up to a factor of 2. Surface area considerations are more complicated but also lead to a predicted one-way underestimate of nucleation rates depending on particle size. This is understood based on the fact that the electrical mobility diameters used in calculating surface area do not account for the shape factors of agglomerate particles such as those shown in Fig. 3. Following Hinds (1999), the spherical equivalent diameter of such particles may be as much as a factor of two smaller than the mobility diameter and the projected area diameter up to about $28 \%$ smaller than obtained by electrical mobility. Consequently, the surface area may be overestimated by up to a factor of 2 and nucleation rate underestimated by a factor of 2 due to the agglomerate particle morphology. A final uncertainty in the nucleation rate calculations relates to the presence of multiply charged particles as discussed in Sect. 2. These larger particles also express their nucleation response following Eq. (6) and will be misinterpreted as contributions from the primary selected particle size. The largest percentage of multiply charged larger particles determined in Sect. 2 lead in this manner to a $30 \%$ contribution to ice formation at the $1 \%$ activated fraction level. Thus, the impact of multiply charged particles is to cause an overestimation of nucleation rate by a maximum of about $40 \%$. All of these uncertainties are rather small in comparison to the range of nucleation rates found in this study, as is described next.

Figure 9 shows nucleation rates for aluminum oxide core particles treated with $\mathrm{H}_{2} \mathrm{SO}_{4}$ compared to the nucleation rates reported by Hung et al. (2003) for aluminum oxide core particles treated with $\left(\mathrm{NH}_{4}\right)_{2} \mathrm{SO}_{4}$, and Fig. 10 shows a similar comparison for the treated iron oxide particles. The results are compared for constant water activities, given that this appears to normalize for differences in the composition of the sulfate coating (see last section). The Hung et al. (2003) nucleation rates were reported as functions of the $\left(\mathrm{NH}_{4}\right)_{2} \mathrm{SO}_{4}(\mathrm{aq})$ mole fraction which we converted to water 
activity using the Aerosol Inorganics Model (AIM) of Clegg et al. (1998). Curve fits as in Figs. 7 and 8 for water-activity based parameterizations were used to associate data from the current study with these same water activities and thus create the data points in Figs. 9 and 10.

Figures 9 and 10 show generally good agreement between the trend of nucleation rates in this study and in the study of Hung et al. (2003). The nucleation rates in this study range to higher values. This was expected because of the particular designs of the different experiments. In the CFDC experiments, the range of nucleation rates realized is closely tied to the residence time and the sensitivity to detecting ice formation from a relatively higher fraction of a lower concentration (few hundred $\mathrm{cm}^{-3}$ ) of aerosol particles, and this process is not affected by mass transfer issues. In the Hung et al. (2003) study, smaller fractions of high concentrations $\left(>10^{6} \mathrm{~cm}^{-3}\right)$ of aerosols typically nucleate and the process is self-limiting during transit through the flow tube due to vapor phase mass transfer to ice crystals from remaining liquid aerosols. The slopes of the nucleation rates in this study are shallower than measured by Hung et al. (2003): for both metal oxides, the constant $a_{w}$ lines for this study are spread across a larger temperature range than those reported by Hung et al. (2003). Uncertainties in nucleation rate due to uncertainties in agglomerate particle surface area and CFDC residence times do not explain this difference. It is possible that the Hung et al. (2003) data may not reflect as large a variation in particle size nucleating ice as assumed from the mode size of the input particle distributions. For example, the small fractions nucleated from the polydisperse populations $(0.000003$ to $0.003 \%$ ) may represent primarily the largest particles in the distributions. It is also possible that the particles used in the respective studies were not of entirely similar morphology. For example, it is possible that our agglomerated particles may provide additional active sites for freezing in concave dimensions which are not present for the approximately spherical particles used Hung et al. (2003). Finally, the different solutes (sulfuric acid in this study versus ammonium sulfate in Hung et al. (2003)) and coating amounts (relatively small weight fractions in this study versus relatively large weight fractions in Hung et al. (2003)) used may have had different impacts. This is not expected based on what is understood about solute impacts on freezing and the fact that even the low weight percent coatings of acid in this study would induce a typical 1.3 diameter particle growth factor by water uptake at the point of ice nucleation. Nevertheless, this discussion is not intended to distract from the fact that the general agreement between the two studies is quite good and the results in the current study extend the nucleation rate observations over a wider range of $J_{\text {hetf }}$ for potential use in numerical parameterizations of ice formation by mineral dusts. For the temperature range assessed thus far, the rates can be reasonably fit by exponentials, as shown in Figs. 9 and 10 .

The nucleation rate results in the present study are extrapolated for water activities equal to 1 by using the in- tercepts from analyses as presented in Fig. 8. The nucleation rates computed for $a_{w}=1$ are shown in Figs. 9 and 10. These calculations predict appreciable heterogeneous freezing nucleation by these mineral particles within dilute activated cloud droplets at relatively warm temperatures, for which confirmatory data can be sought in future studies. Gorbunov and Safatov (1994) report active fractions of around $1 \%$ of $200 \mathrm{~nm}$ diameter $\mathrm{Al}_{2} \mathrm{O}_{3}$ particles nucleating ice by unspecified mechanisms in a laboratory water cloud at $-20^{\circ} \mathrm{C}$, which is broadly consistent with our predictions.

For completeness, we here consider the application of classical nucleation theory to the results, assuming the applicability of the capillarity approximation inherent in the spherical cap model and assuming a uniform distribution of active sites. Nucleation rate is then given by,

$J_{\text {hetf }}=K \exp \left(\frac{-\Delta F_{\text {act }}-\Delta F_{\text {ghet }}}{k T}\right)$.

where $\Delta F_{\text {act }}$ is the activation energy (ergs) for movement of water molecules from the solution to the ice phase, $\Delta F_{\text {ghet }}$ (ergs) is the energy of formation of the critical embryo on the surface, $k$ is Boltzmann's constant, $T$ is temperature and $K$ is the impingement rate of monomers to the critical embryo, taken as constant (see, e.g., DeMott, 2002). The free energy of formation for heterogeneous freezing nucleation may be written

$\Delta F_{\text {ghet }}=\frac{4}{3} \pi r_{g}{ }^{2} f(m, x) \sigma_{\mathrm{i} / \mathrm{s}}$,

where $f(m, x)$ is a geometric factor (Pruppacher and Klett, 1997) that depends, in the case of a spherical cap embryo, on the cosine of the contact angle between the ice embryo and substrate nucleus $(m=\cos \theta)$ and the ratio of the nucleus to ice embryo radius $\left(x=r / r_{g}\right)$. The ice embryo radius $(\mathrm{cm})$ is,

$r_{g}=\frac{2 \sigma_{i / s}}{\rho_{i} L_{e f}\left(\ln \left(T_{0} / T\right) a_{w}^{G}\right)}$,

where $L_{e f}\left(\mathrm{ergs}^{-1}\right)$ is the temperature-dependent "effective" latent heat of formation (Khvorostyanov and Sassen, 1998), ice density $\rho_{i}\left(\mathrm{~g} \mathrm{~cm}^{-3}\right)$ is taken from Pruppacher and Klett (1997), $\sigma_{i / s}$ is the interfacial energy (ergs) of the icesolution interface, $T_{0}$ is the triple point of water, $a_{w}$ is water activity, and $G=R T /\left(L_{e f} M_{w}\right), M_{w}$ being the molecular weight of water and $R$ the universal gas constant.

For these calculations we use $\Delta F_{\text {act }}$ from Tabazadeh et al. (2000), who equate it to the measurable energy for viscous flow. Water activity is determined as a function of temperature and composition based on Clegg et al. (1998). Composition- and temperature-dependent values of $\sigma_{i / s}$ for sulfuric acid/water solutions are estimated indirectly through the application of Antonoff's rule (e.g., $\sigma_{i / s}$ is equal to the absolute difference of the individual surface tensions of ice and solution against air) following Tabazadeh et al. (2000). For the pre-exponential constant $K$, we follow 
Hung et al. (2003) and Fletcher (1969), using a value of $10^{20} \mathrm{~cm}^{-2} \mathrm{~s}^{-1}$ and note, as they have, the relative insensitivity of the calculation to this parameter.

Using the measured freezing temperatures and relative humidities to constrain solution composition for $F_{i}=0.01$ and $\Delta t=10 \mathrm{~s}$ in Eq. (6) and under the various assumptions described above, the contact parameter remains as the adjustable free parameter for achieving the required nucleation rate for theory to agree with experiment for different particle sizes. Best-fit values of $m$ for heterogeneous freezing by different sizes of the experimentally tested metal oxides are given in Table 6 . The result of computations versus experimental results for heterogeneous freezing of 100 and $200 \mathrm{~nm}$ $\mathrm{Fe}_{2} \mathrm{O}_{3}$ particles coated with $\mathrm{H}_{2} \mathrm{SO}_{4}$ (weight $\%$ as given in Table 1) is shown in Fig. 11. This analysis shows that while the form of the $1 \%$ freezing results is approximately reproduced by theory in temperature-humidity space, the particle size dependencies cannot be reproduced without parameterizing $m$ as a function of particle size. This suggests that it would be necessary to invoke active-site parameter formulations of classical theory (Fletcher, 1969; Han et al., 2002) to more closely represent ice formation by metal oxide particles based on observations. Nevertheless, we note that the contact parameters found in best agreement for standard nucleation theory are very similar to those found by Hung et al. (2003) for the metal oxide species examined in common with this study.

We do not attempt here to relate in detail the results from experiments with relatively pure aerosols that may reflect deposition nucleation (Figs. 4a, c, e) to classical theory calculations of this ice formation process. It is clear from representative calculations of this type that the slopes of constant nucleation rate versus temperature surfaces are highly sensitive to the choice of contact parameter of ice against mineral surface and the forms of the free energy of formation and surface tension. For example, with appropriate choices for other terms, the negative $d S_{\text {ice }} / d T$ slope can be achieved by an increasing contact parameter as temperature decreases. The same effect is achieved by increasing either the surface tension or free energy terms at lower temperatures.

\section{Conclusions}

A continuous-flow diffusion chamber was used to characterize the size-resolved ice nucleating ability of several types of submicron mineral particles of potential atmospheric importance at cirrus temperatures. Included in this study were aluminum oxide, alumina-silicate, and iron oxide particles both as single component aerosols and treated with a coating of sulfuric acid. Ice nucleating characteristics were also determined for a desert soil dust sample that is intended as a reference sample for airborne Asian dust. These experiments support a number of conclusions.

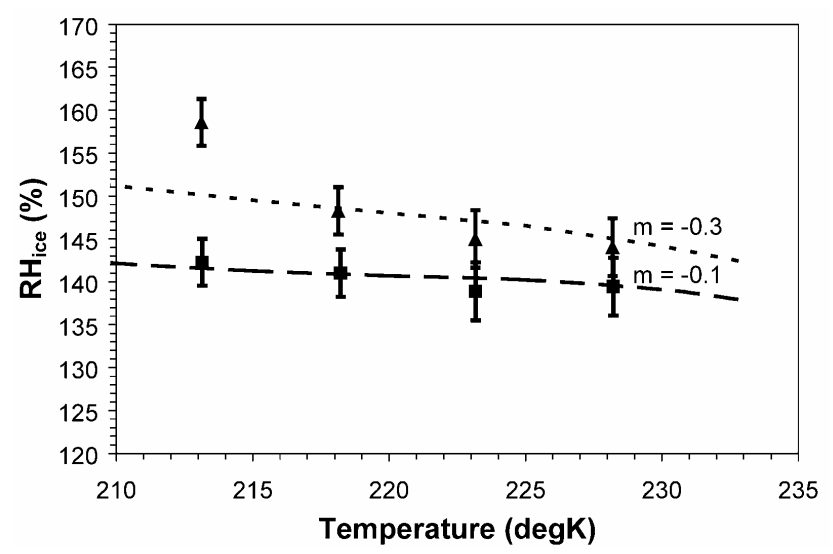

Fig. 11. Comparison of classical theory calculations of heterogeneous immersion freezing nucleation with observations for treated iron oxide particles. The data are the points for activation of $1 \%$ of particles in the CFDC (95\% confidence intervals as error bars). The theoretical calculations are for equivalent $1 \%$ activation, as described in the text. The short (diamond data points) and long dashed (square data points) lines correspond to contact parameters $(\mathrm{m})$ of -0.3 and -0.1 , respectively.

1. The examined particle types, if assumed to be appropriate surrogates for the components of natural mineral dust particles, are strong potential contributors to atmospheric heterogeneous IN populations. This is true whether in the pure state or after being coated with soluble species, such as occurs during processing in pollutant-rich air.

2. The widest range of activation conditions among the aerosol types examined occurred for particles in their pure (unprocessed) state. The ice formation mechanisms could not be discerned in these cases and may have been affected by the preparation or generation methods. The CCN activity demonstrated the presence of some soluble matter, due to contamination, presumably from the dry powders, but possibly redistributed to particles in the water suspensions. Since the deliquescence relative humidity and water uptake properties of the dry particles under the conditions at which ice nucleation occurred were not discernable by the HTDMA method, it was not possible to define ice nucleation as deposition or condensation freezing. If the nucleation mechanism in all untreated cases is presumed to be deposition, particles with diameters of $200 \mathrm{~nm}$ size display constant deposition nucleation rates (equal to $1 \times 10^{-3}$ per particle per second in Figs. 5 and 6) occurring at approximately constant to progressively lower ice supersaturations with decreasing temperature. Future work should consider dry dispersion generation methods.

3. Soluble coatings affected different mineral particles in different ways. Coatings on aluminum oxide particles 
had little impact on altering ice formation as compared to untreated particles, suggesting a condensation freezing mechanism for ice nucleation in both cases. Coatings on iron oxide particles reduced the required $R H_{i}$ for ice initiation by a statistically significant amount in about half of the cases. Coatings on alumina-silicate particles were in most cases detrimental to their innate ice forming ability. The ice nucleation behaviors of the three particle types were similar when coated with significant amounts of sulfuric acid. For the larger particles $(200 \mathrm{~nm})$, coating with sulfuric acid led to heterogeneous freezing under significantly less stringent conditions than those at which the diluted sulfuric acid coatings were predicted to freeze homogeneously.

4. Clear size effects on heterogeneous ice formation were noted for all examined aerosols, independent of nucleation mechanism. In all cases, larger particles consistently nucleated ice at lower humidity than smaller particles at the same temperatures. Particles as small as $50 \mathrm{~nm}$ diameter were active as heterogeneous ice nuclei, with activation conditions that were generally comparable to the homogeneous freezing conditions of small sulfate particles in cirrus conditions. Particles larger than $100 \mathrm{~nm}$ were much more effective heterogeneous ice nuclei. This size dependence is reflected in classical theory of heterogeneous nucleation including active sites and is consistent with observations that suggest that IN typically have sizes larger than $0.1 \mu \mathrm{m}$ (Pruppacher and Klett, 1997; Chen et al., 1998). It is inferred that natural dust particles larger than those studied here (i.e., having diameters larger than $200 \mathrm{~nm}$ ) could be even more effective in initiating ice formation in clouds.

5. Two parametric ice formation models that have been previously applied to model homogeneous freezing nucleation were found to also be conceptually appropriate for describing heterogeneous freezing of coated mineral dust-like particles at cirrus conditions. Both the effective freezing temperature parameterization, for which nucleation rate depends on freezing point depression, and a parameterization that quantifies nucleation rate as a function of water activity could be applied with essentially the same confidence to describe heterogeneous freezing conditions. The range of values of freezing point depression coefficients for heterogeneous freezing $\left(\lambda_{\text {het }}\right)$ determined in this work was consistent with the range that has been reported for homogeneous freezing parameterizations for pure sulfates. Application of these parameterizations requires knowledge of or assumptions of insoluble core size and the amount of soluble material associated with the dust cores. Classical theory may be applied to describe ice formation by coated mineral aerosols, but it is clear that contact parameter must be specified as a function of particle size, or alternately that application of active site theory is necessary.

6. Nucleation rate calculations provide an alternate method for parameterizing ice nucleation by dust particles. These calculations for metal oxide particles suggest that mineral dust particles in supercooled liquid water clouds would initiate ice formation at relatively warm temperatures relevant to mixed-phase clouds.

7. Resuspended, nearly-monodisperse natural desert dust particles activated ice formation at nearly constant ice relative humidities over a wide temperature range ( -45 to $-60^{\circ} \mathrm{C}$ ). The $R H_{i}$ values for nucleating $1 \%$ (in $12 \mathrm{~s}$ ) of the $200 \mathrm{~nm}$ particles from the natural dust sample were the lowest values observed for aerosols tested in the present study, averaging $R H_{i} \sim 135 \%$. The trend of the results predicts lower ice relative humidities for equivalent nucleation rates in larger particles. Since natural mineral dust particle plumes undergoing long-range atmospheric transport include larger submicron and supermicron sizes, the present study suggests airborne mineral dusts as a potential explanation for the presence at cirrus levels of heterogeneous ice nuclei active at or below $130 \% R H_{i}$, as inferred by Haag et al. (2003).

In general, the findings in this study support observations that mineral dust particles can act as efficient ice nuclei (DeMott et al., 2003a, b). These laboratory observations appear to come closer to a viable explanation of the existing observations of the full range of cirrus onset conditions than homogeneous nucleation alone. This information provides more insight into the radiative forcing of clouds, as these particles in competition with homogeneous freezing processes freeze more readily and can lead to a reduction in ice crystal density in slow updraft cloud parcels (DeMott et al., 1997). The net effects on cirrus coverage, properties and net cloud albedo depend also on cloud dynamics (Haag and Kärcher, 2004). Nevertheless, the parameterizations developed here, combined with a prognostic treatment of dust aerosol transport, should be useful in the modeling of ice formation in cirrus conditions, and for interpreting observations of ice formation in clouds. Future studies are needed to extend investigations to other types of natural and surrogate mineral dusts, to improve laboratory methods for examining ice nucleation by such particles in their most genuine state (e.g., without modifications induced by first suspending particles in water), to extend studies to warmer temperatures $\left(T>-45^{\circ} \mathrm{C}\right)$ of relevance to mixed-phase clouds, and to examine the additional effects on ice nucleation rates due to particle processing by gas-phase reactions and clouds. 
Acknowledgements. This work was supported by National Science Foundation Grants ATM0071321 and ATM-0436196. Any conclusions are those of the authors. C. A. Archuleta received partial support for these studies from an American Meteorological Society scholarship. The authors gratefully acknowledge M. Nishikawa of the Japanese National Institute for Environmental Studies for providing the desert soil sample. We also acknowledge the helpful technical and/or manuscript evaluation assistance of D. Rogers, B. Jesse, A. Prenni, K. Koehler, S. Brooks and M. Petters, as well as the helpful comments of our reviewers.

Edited by: M. Ammann

\section{References}

Bassett, D. R., Boucher, E. A., and Zettlemoyer, A. C.: Adsorption studies on ice-nucleation substrates. Hydrophobed silicas and silver iodide, J. Colloid Interface Sci., 31, 436-446, 1970.

Buck, A. L.: New equations for computing vapor pressure and enhancement factor, J. Appl. Meteor., 20, 1527-1532, 1981.

Chen, Y., DeMott, P. J., Kreidenweis, S. M., Rogers, D. C., and Sherman, D. E.: Ice formation by sulfate and sulfuric acid aerosol particles under upper tropospheric conditions, J. Atmos. Sci., 57, 3752-3766, 2000.

Chen, Y., Kreidenweis, S. M., McInnes, L. M., Rogers, D. C., and DeMott, P. J.: Single particle analysis of ice nucleation aerosols in the upper troposphere and lower stratosphere, Geophys. Res. Lett., 25, 1391-1394, 1998.

Clegg, S. L, Brimblecombe, P., and Wexler, A. S.: A Thermodynamic Model of the System $\mathrm{H}^{+}-\mathrm{NH}_{4}{ }^{+}-\mathrm{SO}_{4}{ }^{2-}-\mathrm{NO}_{3}{ }^{-}-\mathrm{H}_{2} \mathrm{O}$ at Tropospheric Temperatures, J. Phys. Chem., 102A, 21372154, 1998.

Cziczo, D. J., Murphy, D. M., Hudson, P. K., and Thomson, D. S.: Single particle measurements of the composition of cirrus ice residue during CRYSTAL-FACE, J. Geophys. Res., 109, D04201, doi:10.1029/2004JD004032, 2004.

DeMott, P. J.: Laboratory studies of cirrus cloud processes, in: Cirrus, edited by: Lynch, D. K., Sassen, K., Starr, D. O. C., and Stephens, G., Oxford Univ. Press, 102-135, 2002.

DeMott, P. J.: Quantitative descriptions of ice formation mechanisms of silver iodide-type aerosols, Atmos. Res., 38, 63-99, 1995.

DeMott, P. J., Sassen, K., Poellot, M., Baumgardner, D., Rogers, D. C., Brooks, S. D., Prenni, A. J., and Kreidenweis, S. M.: African dust aerosols as atmospheric ice nuclei, Geophys. Res. Lett., 30, No. 14, 1732, doi:10.1029/2003GL017410, 2003a.

DeMott, P. J., Cziczo, D. J., Prenni, A. J., Murphy, D. M., Kreidenweis, S. M., Thomson, D. S., Borys, R., and Rogers, D. C.: Measurements of the concentration and composition of nuclei for cirrus formation, Proc. Natnl. Acad. Sci., 100, No. 25, 14655 $14660,2003 b$.

DeMott, P. J., Rogers, D. C., and Kreidenweis, S. M.: The susceptibility of ice formation in upper tropospheric clouds to insoluble aerosol components, J. Geophys. Res., 102, 19575-19584, 1997.

DeMott, P. J., Meyers, M. P., and W. R. Cotton: Parameterization and impact of ice initiation processes relevant to numerical model simulations of cirrus clouds, J. Atmos. Sci., 51, 77-90, 1994.
Dentener, F. J., Carmichael, G. R., Zhang, Y., Lelieveld, J., and Crutzen, P. J.: Role of mineral aerosol as a reactive surface in the global troposphere, J. Geophys. Res., 101, 22 869-22 889, 1996.

Fletcher, N. H.: Active sites and ice crystal nucleation, J. Atmos. Sci., 26, 1266-1271, 1969.

Gorbunov, B. and Safatov, A.: In situ measurements of the iceforming activity of metal oxide aerosols with controlled amounts of surface active groups, J. Aerosol. Sci., 25, 673-682, 1994.

Grassian, V.: Chemical reactions of nitrogen oxides on the surface of oxide, carbonate, soot, and mineral dust particles: Implications for the chemical balance of the troposphere, J. Phys. Chem. A., 106, 860-877, 2002.

Haag, W. and Kärcher, B.: The impact of aerosols and gravity waves on cirrus clouds at midlatitudes, J. Geophys. Res., 109, D12202, doi:10.1029/2004JD004579, 2004.

Haag, W., Kärcher, B., Ström, J., Minikin, A., Lohmann, U., Ovarlez, J., and Stohl, A.: Freezing thresholds and cirrus cloud formation mechanisms inferred from in situ measurements of relative humidity, Atmos. Chem. Phys., 3, 1791-1806, 2003, SRef-ID: 1680-7324/acp/2003-3-1791.

Han, J.-H. and Martin, S. T.: An aerosol chemical reactor for coating metal oxide particles with $\left(\mathrm{NH}_{4}\right)_{2} \mathrm{SO}_{4}-\mathrm{H}_{2} \mathrm{SO}_{4}-\mathrm{H}_{2} \mathrm{O}, 1$ New particle formation, Aerosol Sci. and Technol., 34, 363-372, 2001.

Han, J.-H., Hung, H.-M., and Martin, S. T.: Size effect of hematite and corundum inclusions on the efflorescence relative humidities of aqueous ammonium nitrate particles, J. Geophys. Res., 107(D10), 4086, doi:10.1029/2001JD001054, 2002.

Heintzenberg, J., Okada, K., and Ström, J.: On the composition of non-volatile material in upper tropospheric aerosols and cirrus crystals, Atmos. Res., 41, 81-88, 1996.

Heymsfield, A. J. and Miloshevich, L. M.: Relative humidity and temperature influences on cirrus formation and evolution: $\mathrm{Ob}$ servations from wave clouds and FIRE II, J. Atmos. Sci., 52, 4302-4326, 1995.

Hinds, W. C.: Aerosol Technology: Properties, Behavior, and Measurement of Airborne Particles, John Wiley \& Sons, Inc., New York, 483 pp., 1999.

Hung H.-M., Malinowski, A., and Martin, S. T.: Kinetics of Heterogeneous Ice Nucleation on the Surfaces of Mineral Dust Cores Inserted into Aqueous Ammonium Sulfate Particles, J. Phys. Chem. A., 107, 1296-1306, 2003.

Isono, K., Komabayasi, M., and Ono, A.: The nature and origin of ice nuclei in the atmosphere. J. Meteor. Soc. Japan. 37, 211-233, 1959.

Jensen, E. J., Toon, O. B., Vay, S. A., Ovarlez, J., May, R., Bui, T. P., Twohy, C. H., Gandrud, B. W., Pueschel, R. F., and Shumann, U.: Prevalence of ice-supersaturated regions in the upper troposphere: Implications for optically thin ice cloud formation, J. Geophys. Res., 106, 17 253-17 266, 2001.

Kärcher, B. and Lohmann, U.: A parameterization of cirrus cloud formation: Heterogeneous freezing, J. Geophys. Res., 108, 4402, doi:10.1029/2002JD003220, 2003.

Khvorostyanov, V. and Sassen, K.: Toward the theory of homogeneous nucleation and its parameterization for cloud models, Geophys. Res. Lett., 25, 3155-3158, 1998.

Koop, T., Luo, B. P., Tsias, A., and Peter, T.: Water activity as the determinant for homogeneous ice nucleation in aqueous solutions, Nature, 406, 611-614, 2000. 
Kreidenweis, S. M., Chen, Y., DeMott, P. J., and Rogers, D. C.: Isolating and identifying atmospheric ice-nucleating aerosols: A new technique, Atmos. Res., 46, 263-278, 1998.

Mori, I., Nishikawa, M., Quan, H., and Morita, M.: Estimation of the concentration and chemical composition of Kosa aerosols at their origin, Atmos. Environ., 36, 4569-4575, 2002.

Prenni, A. J., DeMott, P. J., Kreidenweis, S. M., and Sherman, D. E.: The effects of low molecular weight dicarboxylic acids on cloud formation, J. Phys. Chem., 105, 11 240-11 248, 2001.

Pruppacher, H. R. and Klett, J. D.: The Microphysics of Clouds and Precipitation, 2nd edition, Kluwer Academic Publishers, Dordrecht, Boston, 954, 1997.

Roberts, P. and Hallett, J.: A laboratory study of the ice nucleating properties of some mineral particulates, Quart. J. Royal Met. Soc., 94, 25-34, 1968.

Rogers, D. C.: Development of a continuous flow thermal gradient diffusion chamber for ice nucleation studies, Atmos. Res., 22, 149-181, 1988.

Rogers, D. C., DeMott, P. J., Kreidenweis, S. M., and Chen, Y.: A continuous flow diffusion chamber for airborne measurements of ice nuclei, J. Atmos. Oceanic Technol., 18, 725-741, 2001.

Sassen, K., DeMott, P. J., Prospero, J., and Poellot, M. R.: Saharan Dust Storms and Indirect Aerosol Effects on Clouds: CRYSTAL-FACE Results, Geophys. Res. Lett., 30, 12, 1633, doi:10.1029/2003GL017371, 2003.

Sassen, K.: Indirect climate forcing over the western US from Asian dust storms, Geophys. Res. Lett., 29(10), doi:10.1029/2001GL014051, 2002.

Sassen, K. and Dodd, G. C.: Homogeneous nucleation rate for highly supercooled cirrus cloud droplets, J. Atmos. Sci., 45, 1357-1369, 1988.

Stephens, G. L., Tsay, S. C., Stackhouse Jr., P. W., and Flatau, P. J.: The relevance of the microphysical and radiative properties of cirrus clouds to climate and climatic feedback, J. Atmos. Sci., 47, 1742-1753, 1990.
Ström, J., Seifert, M., Kärcher, B., Ovarlez, J., Minikin, A. Gayet, J.-F., Krejci, R., Petzold, A., Auriol, F., Haag, W., Busen, R., Schumann, U., and Hansson, H.-C.: Cirrus cloud occurrence as a function of ambient relative humidity: A comparison of observations obtained during the INCA experiment, Atmos. Chem. Phys., 3, 1807-1816, 2003,

SRef-ID: 1680-7324/acp/2003-3-1807.

Tabazadeh, A., Martin, S. T., and Lin, J.-S.: The effect of particle size and nitric acid uptake on the homogeneous freezing of aqueous sulfuric acid particles, Geophys. Res. Lett., 27, 8, 1111$1114,2000$.

VanCuren, R. A. and Cahill, T. A.: Asian aerosols in North America: Frequency and concentration of fine dust, J. Geophys. Res., 107, 4804, doi:10.1029/2002JD002204, 2002.

Van den Heever, S. C., Carrio, G., Cotton, W. R., DeMott, P. J., and Prenni, A. J.: Impacts of nucleating aerosol on Florida convection, Part I: Mesoscale simulations, J. Atmos. Sci., accepted, 2005.

Wiedensohler, A.: An approximation of the bipolar charge distribution for particles in the submicron size range, J. Aerosol Sci., 19, 387-389, 1988.

Wyslouzil, B. E., Carleton, K. L., Sonnenfroh, D. M., and Rawlins, W. T.: Observation of hydration of single, modified carbon aerosols, Geophys. Res. Lett., 19, 2107-2110, 1994.

Zhang, Y. and Carmichael, G. R.: The role of mineral aerosol in tropospheric chemistry in East Asia - a model study, J. App. Chem., 38, 353-366, 1999.

Zuberi, B., Bertram, A. K., Cassa, C. A., Molina, L. T., and Molina, M. J.: Heterogeneous nucleation of ice in $\left(\mathrm{NH}_{4}\right)_{2} \mathrm{SO}_{4}-\mathrm{H}_{2} \mathrm{O}$ particles with mineral dust immersions, Geophys. Res. Lett., 29(10), 1504, doi:10.1029/2001GL014289, 2002. 